ISSN: $1130-3743$

\title{
¿QUÉ ES SER PROFESIONAL DOCENTE?
}

\author{
What it means to be a profesional teacher?
}

\begin{abstract}
Jaume SARRAMONA LÓPEZ*, Joana NOGUERA ARROM** y Julio VERA VILA***
* Universitat Autònoma de Barcelona. Departament de Pedagogia Sistemàtica y Social. Edifici G-6. 08193 Bellaterra (Barcelona). ** Universidad Rovira $i$ Virgili. Departamento de Pedagogía. Facultad de Ciencias de la Educación y Psicología. Carretera de Valls, s/n. 43007 Tarragona. ${ }^{* * *}$ Universidad de Málaga. Departamento de Teoría e Historia de la Educación. Facultad de Ciencias de la Educación. Campus de Teatinos. 29071 Málaga.
\end{abstract}

BIBLID [(1130-3743) 10, 1998, 95-144]

\section{RESUMEN}

En este trabajo se pretende repensar algunos puntos claves del debate reciente sobre la profesionalización docente, analizando en concreto las tres cuestiones siguientes: ¿Qué es una profesión? ¿Cuáles son los rasgos diferenciales de la misma? ¿En qué medida podemos afirmar que el profesorado cumple los requisitos convencionales de las profesiones? Aunque hay un acuerdo generalizado acerca de la necesidad de mejorar el status profesional de la enseñanza, no hay coincidencia en la forma de conseguirlo. Para entender las diferentes posiciones, se analizan, además, los conceptos de profesionalismo y profesionalización, y se destaca la importancia de la formación como un proceso de desarrollo personal y profesional. Por último se tratan aspectos relacionados con la salud laboral y las enfermedades profesionales.

\section{SUMMARY}

This article proposes to rethink some of the key issues of the recent debate about the teaching profession, through the analysis of three specific aspects: What is a profession? What are its distinctive features? To what extent can we say that teachers are satisfying the demands of the profession? Although there is a general agreement about the need to improve the professional quality of teaching, there doesn't seen to be a way to achieve it. In order to understand the different points 
of view, there will also be an analysis of the notions of professionalism and professionalization, with an emphasis on the importance of formation as professional and personal development process. To conclude, the issues of laboral health and professional illnesses will be dealt with.

\section{LA PROFESIONALIZACIÓN DE LA ENSEÑANZA. TEMA RECURRENTE EN LAS REFORMAS EDUCATIVAS}

Uno de los temas recurrentes en la literatura pedagógica actual es el de la profesionalización del profesor. Tema que se considera íntimamente vinculado a la mejora de la calidad de la educación pretendida en las numerosas reformas ocurridas, tanto en nuestro país como en la mayoría de países de nuestro entorno. Constituye una evidencia la relación entre la innovación educativa y la preparación y actitud coherente del profesorado para llevarla a cabo.

Así, por ejemplo, refiriéndose al ámbito de Estados Unidos, Abdal Hagg (1995) apunta cómo desde los años 70, un buen número de propuestas para mejorar la educación pública americana han incluido una llamada para elevar la enseñanza al "status de una verdadera profesión". En 1976 la Asociación Americana de Colegios, en el Informe que elaboró para el Bicentenario de la Formación del Profesor, urgió un esfuerzo profesional y de organización en esa dirección. Igualmente en "Los profesores del mañana" el grupo Holmes se propuso como objetivo principal «la transformación de la enseñanza de una ocupación a una profesión genuina" (1986). Covalewski (1994) añade cómo también la "Carnegie Commission" para el avance de la enseñanza en los mismos años 80, sugirió la necesidad de profesionalizar la enseñanza y, aunque reconocía que cada movimiento entendía la profesionalización de forma peculiar, sí había acuerdo general en que la misma tenía que realizarse sobre la base de conocimiento comparable al conocimiento especializado de médicos y abogados. De ahí que muchos reformistas concretaran su objetivo proponiendo mejoras en la preparación de los profesores.

Como ejemplo reciente de la importancia concedida en Europa al tema, cabe destacar la celebración en julio de 1993 del 3. ${ }^{\text {er }}$ Seminario Internacional de la ATEE (Association for Teacher Education in Europe), con el lema "la profesionalización de la enseñanza y de los profesores". Dicho Seminario se realizó en Barcelona, bajo los auspicios de las Comunidades Europeas, la Generalitat de Catalunya y el Colegio de Doctores y Licenciados, y en él se presentaron informes sobre el estado de la cuestión en dieciocho países europeos y en USA. Todos los informes, tanto de uno como del otro lado del Atlántico, manifestaron explícitamente que no se ha logrado una profesionalización satisfactoria, apuntando la mayoría, después de una reflexión sobre la naturaleza de las profesiones y su función en el mundo actual, algunas propuestas orientadas a conseguirlo.

Concretamente en nuestro país, la reflexión sobre la situación de la profesionalización de las profesiones pedagógicas, tiene una larga tradición que ha corrido pareja con los cambios sociopolíticos acontecidos y las grandes transformaciones ocurridas en nuestro sistema educativo con la LGE de 1970, la LODE de 1985 
y la LOGSE en 1990. Dicha reflexión ha dado lugar a numerosas publicaciones objeto de consulta bibliográfica.

En todas ellas podemos descubrir los diferentes enfoques dados a la cuestión, surgidos como respuesta a las circunstancias sociopolíticas citadas, a la propia evolución del pensamiento pedagógico y, sobre todo, a la difusión de los diferentes modelos o paradigmas de formación. Así por ejemplo, en el número monográfico dedicado al tema por la Revista de Educación (1988) la tónica de la mayoría de artículos estaba en subrayar el cariz político, es decir, de poder, que toda estructura profesional conlleva (Popkewitz; Sargati, etc.) y la necesidad que ello supone de promover una práctica profesional crítica. En el número de Cuadernos de Pedagogía (1993) el carácter dominante era la insistencia en la formación de profesionales reflexivos.

En un rápido análisis comparativo entre la situación de los profesionales de la educación de los años 70 y 80 con la actualidad es fácil detectar grandes cambios, como son, por ejemplo, la creación de las Facultades de Educación, la incorporación del título de Psicopedagogía entre las especialidades a desempeñar en los centros docentes y, en consecuencia, su integración como especialidad en las oposiciones al respecto, la creación del título de Educador Social y su progresiva implantación en áreas concretas del trabajo social, etc. Junto a ello hay que constatar cómo proyectos altamente positivos se quedaron en el camino, como por ejemplo, la construcción de una carrera de Formación de Profesores no sólo para la Educación Primaria, sino también para la Educación Secundaria.

Por último, hemos de reconocer que las duras constataciones apuntadas por ejemplo por Sarramona, Ortega, García Carrasco y otros, en el VII Congreso Nacional de Pedagogía de 1980, permanecen vigentes y continúa siendo una tónica permanente la dificultad extrema que encuentra el pedagogo y el docente, para obtener un reconocimiento profesional que esté en coherencia con la importancia real del papel de la educación en el seno de la sociedad.

En este trabajo se pretende, con la aportación de algunas reflexiones producidas en debates recientes sobre el tema, repensar algunos de sus puntos clave a partir del concepto de profesión y de sus características, analizando en concreto las tres cuestiones siguientes:

¿Qué es una profesión?

¿Cuáles son los rasgos diferenciales de la misma?

¿En qué medida podemos afirmar que el profesorado cumple los requisitos convencionales de las profesiones?

Todo ello porque tal reflexión y las consecuencias que de ella se extraigan pueden ser elementos que incidan directamente sobre la calidad de la educación pretendida, porque "ganar en espacios de profesionalidad supone ganar en democracia, autonomía, control y responsabilidad" (Imbernón, 1994, p. 14).

\section{El CONCEPTO DE PROFESIÓN, LA PROFESIONALIZACIÓN Y EL PROFESIONALISMO}

El análisis de las profesiones como tales debe su empuje a los estudios de sociología de las profesiones que destacaron la importancia de considerar las ca- 
racterísticas de las mismas desde sus perspectivas política, social e histórica, además de la propiamente específica o científica de su ámbito de conocimiento.

Definir qué es una profesión es difícil, porque el término designa una realidad compleja y, por ello ha recibido diferentes significados según los países o las épocas históricas.

\subsection{La profesionalización como proceso}

La primera consideración que cabe hacer es que toda profesión es trabajo, pero no a la inversa, de manera que este concepto parece estar restringido a algunas modalidades concretas, vinculadas al fenómeno de la división del trabajo y al de la especialización, que se prestaban bien a la organización gremial o corporativa.

A tenor de su evolución histórica, las profesiones no son un producto de las sociedades avanzadas. Más bien contienen algunos elementos anacrónicos que son restos de su origen religioso y de las organizaciones gremiales de la Edad Media, a los que se añade lo que es propio de la época actual: su expansión, su desmembración y la pérdida de algunos rasgos tradicionales. En cierto sentido, lo profesional es sinónimo de imparcialidad, de ausencia de arbitrariedad, de responsabilidad frente al amateur, de calidad en el servicio, de entrega generosa, de esmero en el modo de realizar el trabajo, de competencia. No faltan, sin embargo, quienes ven a las profesiones como una forma encubierta de autoritarismo, reductos de un pasado en retroceso en las que anidan el elitismo, el privilegio y el monopolio.

En sus orígenes, el concepto está relacionado con la profesión clerical. En la concepción clásica de Spencer o Durkheim, las instituciones profesionales nacen de ciertas funciones sagradas que en principio fueron asumidas por los sacerdotes y que van sufriendo una diferenciación progresiva y una creciente complejidad. Antes del siglo XVI ser profesional era hacerse religioso, comprometerse con una orden monacal, sometiéndose a las normas a través de los votos de obediencia, pobreza y castidad. Como dice Wanjiru «ser profesional, cuando se empezó a utilizar el término, significaba haber hecho un voto explícito o implícito de guardar ciertas normas en comunidad con otras personas, igualmente dedicados y profesados. En eso residía la dignidad y el honor de ser profesional" (1995, p. 162).

Más tarde, a partir del siglo XVI, el término pierde su significado ascético, pero conserva ciertas reminiscencias religiosas como el concepto de vocación, de servicio a los demás o de renuncia a los intereses materiales. Probablemente fue Martín Lutero el primero en usar el vocablo profesión (Beruf) desprovisto de sus matices ascéticos pero con un peculiar sentido dogmático del deber de trabajar, impuesto por la divinidad y al que uno ha de supeditarse. En su concepción, la vida contemplativa y ascética se considera puro egoísmo, por lo que no es un camino de salvación, mientras que el trabajo profesional es un deber para con el prójimo, una expresión de la conducta moral y una forma de corresponder al amor de Dios. La profesión es la vocación al trabajo en el mundo (Cfr. Ibíd., pp. 164-167).

A partir del siglo XVII surge el concepto moderno de profesión, vinculado al desarrollo de la ciencia y la tecnología. En adelante, la especialización científica 
será uno de los factores determinantes del trabajo profesional y uno de los criterios para la jerarquización dentro de ese sector. La ciencia empírica adquiere un estatuto privilegiado como fuente de saber positivo y fiable del mundo, a la vez que la práctica alcanza su máximo reconocimiento como forma de alcanzar los objetivos prefijados a través de la selección de los medios apropiados y legitimados científicamente.

El resultado de esa nueva concepción fue el auge de la Ingeniería y la Medicina como saberes prácticos, eficaces y capaces de explicar por qué y cómo. Por el contrario, los trabajos que no pudieron aplicar esa racionalidad tecnológica se vieron poco a poco rechazados como oficios, trabajos o artes, que requieren habilidad, pero sin base científica. Sin embargo, el carácter científico es sólo uno de los componentes que contribuyeron a distinguir unas ocupaciones de otras, como veremos a continuación.

Para Wilensky (1964), la profesionalización es un concepto dinámico que expresa el tránsito de ciertas ocupaciones a una creciente profesionalización, por imitación de ciertas características de las profesiones ya establecidas. Es la secuencia temporal que siguen las distintas ocupaciones para tratar de adecuarse al tipo ideal de profesión liberal que toman como modelo de referencia las profesiones más recientes, las que podríamos considerar semiprofesiones, o simplemente, las distintas ocupaciones que aspiran a serlo. En ese tránsito se van consolidando unas etapas: la dedicación plena a una actividad, la posesión de unos conocimientos de rango superior, la constitución de una asociación profesional y otros que, como veremos, caracterizan el modelo clásico de profesión liberal.

Efectivamente, cuando la sociología actual estudia la profesionalización de una ocupación, suele comprobar si cumple con una serie de características que se le atribuyen al modelo tradicional de profesión liberal. Así, desde el punto de vista de la autonomía pueden darse casos de auténtica profesionalización, de semiprofesionalización y de desprofesionalización. Las semiprofesiones representan un grado menor de profesionalización porque sólo alcanzan la autonomía en algunas de las características típicas, como sería para algunos el caso de los profesores; mientras que la desprofesionalización supone un proceso de pérdida de autonomía a través de la intervención de instancias externas, como la del Estado. Los obreros serían dentro de este esquema el extremo opuesto de los profesionales, con menor nivel de conocimientos académicos, muy bajos niveles de control sobre sus procesos de trabajo y muy escasa capacidad de autonomía (Tenorth, 1988, pp. 82-84; Fernández Enguita, 1990, pp. 150-151).

Sin embargo, utilizar este criterio taxonómico lleva a que cada profesión colme algunos requisitos pero se quede lejos de cumplir algunos otros, por lo que intentar trazar una línea definitiva para diferenciar entre profesiones, semiprofesiones y no profesiones es muy difícil. "Las características que definen el concepto de profesión no son condiciones necesarias y/o suficientes para otorgar la condición de profesión en una actividad, [...]" (Touriñán, 1990, p. 11), porque su presencia o ausencia es cuestión de grado, y probablemente, no hay ninguna ocupación que las cumpla todas de manera inequívoca. Los intereses corporativistas e ideológicos de cada grupo, hacen que cada uno resalte precisamente aquellas 
características que más le favorecen, lo cual resulta lógico, si contemplamos el fenómeno de la profesionalización como una variable evolutiva, sujeta a cambios históricos.

El concepto de profesión está socialmente construido, ni es neutro ni estrictamente científico; es en cada momento, el resultado de un marco social, cultural e ideológico que exige ser estudiado en sus condicionantes sociales e históricos. Por lo tanto, parece razonable pensar que la profesión no consiste tanto en una lista precisa de rasgos que cumple un trabajo de forma fija e inmutable, sino un proceso continuo de búsqueda y perfeccionamiento para el logro de una serie de objetivos (Imbernón, 1994).

\subsection{Las distintas concepciones del término profesión}

Una profesión en principio es una ocupación social mediante la cual uno se puede ganar la vida (García Carrasco, 1988, p. 622). Teniendo en cuenta que el dinamismo de los tiempos hace variar el concepto de profesionalidad y que ésta no se puede vincular con la exclusiva tradición de las profesiones liberales, una definición que proponemos es la siguiente: "se entiende por profesión aquel conjunto de actividades específicas que, fundamentadas en conocimientos científicos y técnicos, se aplica a la resolución de problemas sociales".

Los autores suelen proponer una lista de características propias de la profesionalidad, por ejemplo Hoyle (1974), si bien luego se suele hacer énfasis en algunas de ellas, dependiendo de la perspectiva donde se sitúan. Pratte y Rury (1991) resumen en cuatro los criterios que dan forma a la visión tradicional de una profesión: remuneración, status social, poder autónomo o autorizado, y servicio. Burbules y Densmore (1992) denominan el enfoque típico de la reforma americana hacia la profesionalización del profesor como enfoque taxonómico, pues se centra en una lista de características que son típicas de ocupaciones que han sido tradicionalmente consideradas como profesiones, especialmente en Derecho y Medicina. Estas características son: autonomía profesional; un conocimiento base claramente definido, altamente desarrollado, especializado y teórico; control de la instrucción, certificación y autorización de nuevos candidatos; poder legitimado especialmente en relación a la ética profesional; obligación al servicio público. Case et al. incluyen la presencia de un colegio profesional; Sockett (1990) distingue entre la profesionalización o proceso por el cual una ocupación llega a ser una profesión, y el profesionalismo, el cual describe la cualidad de la práctica.

Bourdoncle (1994), distingue el sentido que las palabras "profesión" y "profesionalización" tienen en francés y en inglés y, en correspondencia, en los países latinos o en los anglosajones. El sentido francés subraya el significado semántico de la palabra como profesión de fe, es decir declaración pública de las creencias. Según esta primera característica la profesión se refiere a una actividad en la cual los saberes para ejercerla son transmitidos públicamente y no de forma iniciática o misteriosa. En segundo lugar la profesión tiene en común con la ocupación el que constituye un medio de vida. La tercera característica se aproxima al sentido anglosajón, al definir la profesión como un oficio que tiene un cierto prestigio por 
su carácter intelectual o artístico, o por la posición social de los que la ejercen como son las de abogado, médico o "proffesseur".

En el sentido inglés la profesión se define fundamentalmente como una vocación, un oficio que está fundamentado en alguna rama del saber o de la ciencia, citándose igualmente la Medicina, el Derecho y la Enseñanza.

En Francia y países de Europa del Sur predomina la segunda característica sobre cualquier otra, es decir la que no distingue profesión de oficio, mientras que en Inglaterra y América del Norte la consideración más diferenciadora es la del prestigio social.

El autor citado, a efectos de poder sintetizar las aportaciones de los países participantes en el III Seminario de la ATEE mencionado anteriormente, distinguió el sentido del término profesionalización según que se aplicase a los siguientes ámbitos:

1. Al status de una actividad en sí misma y del grupo de personas que la ponen en práctica. Es algo más que el oficio.

2. A los conocimientos y capacidades que exige la actividad. Así profesionalización es el proceso de mejora de las capacidades y de racionalización de los saberes puestos en práctica, lo cual redunda en una mayor destreza y eficacia.

3. Al individuo o sujeto que se ha profesionalizado que domina cada vez mejor la actividad y responde a las normas establecidas colectivamente por el grupo profesional.

4. A la formación. Proceso fuertemente orientado hacia la actividad profesional, tanto en sus contenidos como en sus formadores.

El siguiente cuadro resume las características apuntadas (Bourdoncle, 1994).

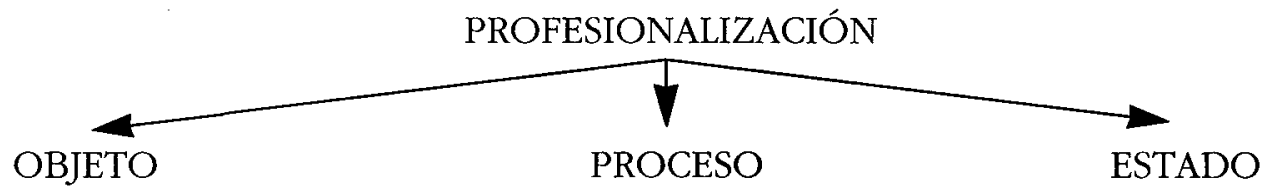

1. Grupo que ejerce una actividad. Status.
Monopolio de la actividad. Autonomía. Elevación de status.
Profesionalismo colectivo "profesionismo" corporativismo.

2. Saberes unidos a la Crecimiento en especificidad, Profesionalidad. actividad. racionalidad y eficacia.

3. Individuo que ejerce la actividad.
Socialización profesional: adhesión individual a las normas colectivas.
Profesionalismo individual.
Orientación más fuerte hacia la profesión.
Formación profesionalizada.

EsQuema 1. Ámbitos de aplicación del concepto profesionalización" según Bourdoncle (1994). 


\subsection{La crítica al profesionalismo y la crisis del modelo tradicional de profesión liberal}

Cuando las características del modelo de profesionalidad descritas son asumidas por los profesionales para justificar sus diferencias y privilegios o para legitimar sus intereses y sus deseos de movilidad, podemos hablar de profesionalismo como ideología (Martín-Moreno, y De Miguel, 1982, p. 53). En este sentido, los críticos del modelo, consideran que esas características no son sino propuestas ideológicas que las profesiones emiten para lograr apoyo social a sus privilegios.

Para Freidson $(1978$, p. 15) la profesión es una ocupación que a través de una posición de predominio en la división del trabajo ha conseguido el control para determinar la esencia de su propio trabajo, esto es, ha conseguido convencer a los ciudadanos de que no hay otro modo mejor de garantizar un buen servicio en su campo de actividad que siendo ellos mismos quienes regulen las condiciones de su trabajo.

Sin embargo, la experiencia nos demuestra que el status y el poder de las profesiones no dependen necesariamente ni de la vocación de servicio, ni del carácter especializado de los conocimientos. Cuando hablamos del carácter intelectual, independiente y desinteresado de las profesiones, estamos resaltando sólo la parte más noble y defendible del modelo, pero ésta no lo es todo, ya que de hecho es raro el profesional renombrado que no gane mucho dinero. Por ello, para algunos autores la idea de monopolio es esencial para comprender el peso de cada actividad en la jerarquía social y para explicar la ideología del profesionalismo (Larson, 1979).

Es el ejercicio del monopolio el que permite regular el acceso a la profesión, de manera que ésta no se masifique, conserve su carácter elitista y reporte unos ingresos elevados. "Se trata de la supervivencia de un sistema estamental que busca en la idea de servicio y respetabilidad, en el desinterés y en el conocimiento para resolver problemas humanos, la manera de situarse en una cómoda jerarquía, ajena a la disciplina que sigue el resto de los trabajadores" (Martín-Moreno, y De Miguel, 1982, p. 61).

El modelo profesional monopolístico era razonable cuando sólo unos pocos podían acceder al título, pero entra en crisis por la presión de los jóvenes titulados que no encuentran trabajo y han de dedicarse a otras actividades, o pasar a ser asalariado o interino o contratados, ya sea en la empresa pública o en la privada. Es exactamente lo que está ocurriendo actualmente con los farmacéuticos y los requisitos para regular el número de farmacias por habitante. El principio monopolístico es defendido por los profesionales ya instalados, mientras que los que todavía no lo han conseguido esgrimen el argumento de la libre competencia. Por otra parte, cuando todos los ciudadanos reclaman su derecho a la sanidad, a la educación, o a la defensa ante los tribunales, el Estado ha de intervenir para garantizar esos derechos, más allá del altruismo de los profesionales, que es insuficiente.

El profesional liberal, con estudios universitarios y que trabaja por cuenta propia, es hoy en día una dedicación minoritaria o complementaria del trabajo asalariado dependiente de grandes instituciones como los bufetes, las editoriales, los hospitales, los grandes laboratorios, las empresas de servicios, etc. Muchos profe- 
sionales trabajan agrupados en estudios, gabinetes, despachos, o son empleados de la Administración, en donde se combina el trabajo burocratizado, con la jerarquía y la independencia. En definitiva, la condición de asalariado no es contradictoria con la de profesional, ya que si en algún sentido se puede decir que las administraciones burocratizan a los profesionales, también se puede decir que éstas se profesionalizan. El prestigio que antes era de un solo profesional, ahora se distribuye entre todos los que participan en una trama organizativa.

El sector profesional es dinámico y si bien es cierto que algunas profesiones decaen, o ciertas características se debilitan, también es cierto que otras nuevas aparecen. Por ejemplo, el carácter asalariado de una parte del sector profesional hace que sus formas de asociacionismo se diversifiquen, con una mayor presencia del sindicalismo o de las asociaciones sectoriales al margen o junto a los colegios. También el carácter monopolístico cede paso a los mecanismos de mercado como la libre competencia, donde se hace más difícil la defensa de los intereses corporativos. Del mismo modo, muchas empresas ya no contratan para sus cargos técnicos o directivos sólo atendiendo a la titulación, sino bajo el supuesto de que la formación especializada la va a dar la propia empresa para lo cual admite una cierta equivalencia de titulaciones aptas para el desempeño de las funciones específicas que requiere. Todos estos elementos demuestran que el sector profesional es complejo y diverso.

No se puede suponer que las profesiones van a desaparecer de la noche a la mañana, pero sí resulta razonable pensar que algunos elementos definitorios del modelo están experimentando cambios sustantivos. No hay tal comunidad de profesiones como imaginaba la sociología parsoniana. Cada profesión es un mundo y difícilmente se puede generalizar a las demás. El hilo conductor sigue siendo el modelo de profesionalidad que, como estamos viendo, se realiza de muy distinta manera según los casos" (Ibíd., p. 152). La propia división del trabajo que dio origen a las profesiones, introduce algunas especialidades nuevas sobre el tronco clásico, altera sus características, hace compatible el trabajo libre con el dependiente, diversifica las funciones, y lo mismo que compromete la supervivencia de algunas, hace emerger otras nuevas.

La fuerza de las profesiones más antiguas se ha sostenido en la organización colegial, por eso la crisis de estas organizaciones refleja también las transformaciones que están experimentando las profesiones. El colectivo se debilita en la medida en que sus miembros tienen situaciones de trabajo dispares o incluso encontradas, o cuando los jóvenes titulados no se sienten representados por los veteranos que tienen una posición mucho más acomodada y que definen la política a seguir por la organización colegial. Por eso, frente al colegio, surgen para los profesionales otras formas de asociación que pretenden ser más flexibles y menos corporativas, como las sociedades científicas, las asociaciones por especialidades, los sindicatos de técnicos, o la sindicación tradicional de clase de la que serían más partidarios los más críticos con la ideología del profesionalismo.

Hay al menos tres notas que caracterizan la situación actual del ámbito de las profesiones: a) la falta de criterios que permitan definir inequívocamente al profesional; b) que en la sociedad actual la profesionalización es una tendencia de- 
seable, porque supone mayor garantía de calidad, en la realización de determinadas funciones, sobre la base de una competencia adquirida a través de un proceso de formación, acreditado con un título; y c) que cada día hay más trabajadores que desean ser considerados profesionales, porque ser catalogado como tal supone adquirir una relevancia social que permite sentirse dentro de una elite en lo económico y/o en lo social.

A pesar de estas legítimas aspiraciones, cabe preguntarse si en el momento actual se puede seguir hablando de profesiones en el sentido tradicional. Si antes uno de los rasgos que las distinguía de otras ocupaciones era su carácter elitista, restringido y escaso, ahora se han masificado y más bien parece observarse un aumento de la democratización, la participación y el nivel de exigencia de los ciudadanos.

Puesto que no es seguro que la historia camine progresivamente hacia el cumplimiento de los requisitos ideales de las profesiones clásicas, quizás tenga más sentido plantearse la profesión como un proceso cultural de mejora permanente, que, en el caso del profesorado, puede influir en la calidad de la enseñanza y en el propio autoconcepto, y que es cada vez más necesario en una sociedad en cambio. Por lo tanto, trabajar por mejorar la profesión, no significa necesariamente defender la ideología del profesionalismo, al menos en sus versiones clasistas de la sociedad. Más bien, como señala Imbernón (1994, p. 20), la profesión docente ha de significar el compromiso con una forma de trabajo en los espacios educativos basada en la reflexión, en la investigación, en la innovación en torno a los problemas de la práctica que la mejoren y que vaya dando paso a una nueva cultura profesional construida desde el trabajo en equipo y orientada hacia un mejor servicio a la sociedad. Todo ello reclama cambios en la concepción de la figura del profesor que son a los que nos queremos referir cuando empleamos la expresión profesionalización docente.

Sobre el profesionalismo en la enseñanza, Sykes (1992) en su defensa y Burbules y Densmore (1992 a y b) en su contra, representan los argumentos de la polémica. En nuestra opinión, es posible avanzar en la profesionalización de la enseñanza, sin que ello represente un peligro para el derecho de la sociedad a participar en el debate educativo, sin que suponga la exclusión de la profesión de minorías marginadas socialmente a través del control del acceso, y sin que necesariamente se imponga un modelo tecnocrático que suponga una desprofesionalización real de los profesores, en beneficio exclusivo de una minoría de técnicos superiores. Como dice Sykes (1992):

"Sostengo que cualquier estrategia comprensiva debe incluir un componente profesional [...]. Son dignas de tener en cuenta, no obstante, las advertencias de Burbules y Densmore acerca de los peligros de la jerarquía, de la distancia respecto a los padres y la comunidad y de la exclusión de las minorías. Pero pueden construirse ideales profesionales que den cabida a la igualdad, a las diferencias instrumentales de status entre los profesores y a la colaboración con los padres en la educación de los jóvenes. Me atrevería a afirmar que sin las virtudes características del profesionalismo cualquier otra reforma quedaría incompleta y no penetrada hasta el núcleo de la cuestión: la mejora de la instrucción" (p. 96). 


\section{Profesionalidad en el Ámbito educattvo}

\subsection{Profesionales de la educación y funciones pedagógicas}

La mención a la profesionalidad educativa abre ciertos interrogantes que no se plantean en otros ámbitos. ¿Podemos utilizar el término "profesional" con todas sus consecuencias para referirnos al profesorado, como sujeto más representativo de agentes educadores? ¿Acaso se trata de un "semi-profesional", tal como señalan algunos autores? La cuestión es si podemos aplicar el concepto de profesionalidad a la actuación educativa con los mismos parámetros que lo hacemos para otras actividades, cuando resulta que la educación nos implica de manera tan directa a todos y existe desde que existe la humanidad misma.

La primera consideración que cabe hacer es que al contemplar la posibilidad de que sea realizada de manera profesional, no nos referimos a la educación en sentido totalmente amplio sino a una acción educativa que se lleva a cabo con unas determinadas condiciones. Esto invalida que a los profesionales de la educación les podamos aplicar la denominación genérica de «educadores, sin más, porque educadores lo son también los padres, los tutores, y otras figuras que merecen tal apelativo. La alternativa puede ser la denominación de profesores o, si se quiere utilizar una denominación más genérica, el profesorado. Pero entonces dejamos de lado toda una serie de agentes que intervienen directamente en la educación formal y no formal en calidad de planificadores, orientadores, evaluadores, gestores, elaboradores de recursos, etc., entre los cuales destacan precisamente una gran parte de los licenciados en Ciencias de la Educación o equivalentes. Y ello porque está claro que la actividad educativa desborda la docencia de las materias curriculares, si bien bajo lo que denominamos "docencia" también se incluye la realización de otras actividades.

Desde otra perspectiva, y siguiendo a Touriñân (1990), son profesionales del sistema educativo todos aquellos que trabajan en él, ya sea como psicólogos, médicos, sociólogos, etc. Pero sólo son profesionales de la educación, aquellos cuya tarea «es intervenir, realizando las funciones pedagógicas para las que se han habilitado". Por lo tanto, no todo profesional del sistema educativo lo es de la educación, si no han sido formados en el conocimiento de la educación ni en la realización de funciones pedagógicas, como tampoco los especialistas en funciones pedagógicas son los únicos responsables de la estructura, el proceso o el producto del sistema educativo (pp. 18-19).

Lo que distingue a los profesionales de la educación es su competencia y habilitación en funciones pedagógicas, que son actividades específicas basadas en el dominio de aquel conocimiento autónomo de la educación que permite generar decisiones pedagógicas, y cuyo concurso es necesario para satisfacer la demanda social de calidad en la educación.

Es posible identificar al menos tres tipos de funciones pedagógicas distintas, en función del crecimiento del sistema escolar y del conocimiento del fenómeno educativo:

- Funciones de docencia.

- Funciones de apoyo al sistema educativo.

- Funciones de investigación. 
Todas ellas son funciones pedagógicas porque requieren competencias adquiridas con el conocimiento de la educación. Pero, a la vez, son diferentes, porque cada tipo de función tiene unas características exclusivas que le dan sentido y que requieren competencias pedagógicas específicas. Además, cada una de estas funciones se puede, a su vez, diversificar, si existe diversificación en el ámbito en el que se aplican. Así, por ejemplo, puede haber diversificación en la función docente, cuyo núcleo pedagógico de formación no es exactamente igual para profesores de preescolar, primaria, secundaria o universidad. Igualmente, el director de un centro y el inspector, realizan funciones de apoyo, pero diversificadas, porque las competencias pedagógicas requeridas para ejercer una u otra función no son las mismas (Ibíd., p. 21).

Ahora bien, de todo lo dicho, no se debe concluir que función pedagógica y profesión sean la misma cosa, ya que con una sola habilitación profesional una persona puede capacitarse para realizar diversas funciones pedagógicas. Eso ocurre con la profesión de profesor que no consiste sólo en la función docente, aunque sea la más significativa. Lo que identifica a todos los profesionales de la educación es el conocimiento pedagógico, es decir "el conocimiento de la educación específico que los capacita para explicar, interpretar y decidir la intervención pedagógica propia de la función para la que se habilitan" (Ibíd., p. 22). En consonancia con estos argumentos, las áreas culturales (historia, literatura, física, etc.) forman parte de la educación, pero puesto que no son conocimiento de la educación, pueden perfectamente cursarse en otras Facultades distintas a aquellas que forman a los especialistas en funciones pedagógicas, sobre la base de núcleos pedagógicos de formación parcialmente coincidentes, es decir, las Facultades de Pedagogía o de Ciencias de la Educación, según los sitios.

El siguiente esquema quizás sea útil para esquematizar estas reflexiones:

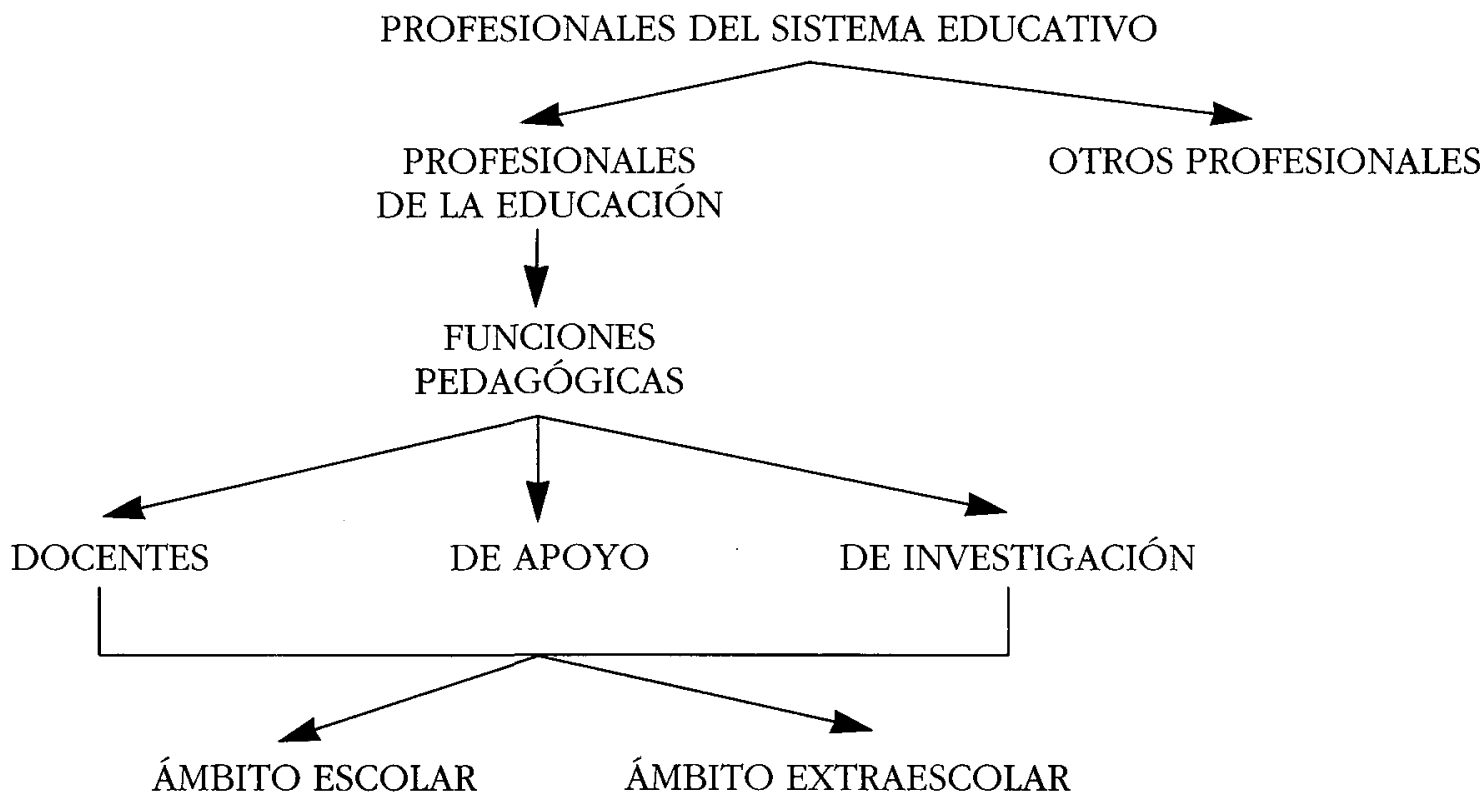

EsQuema 2. Profesionales del sistema educativo. Funciones pedagógicas y ámbitos de intervención. 
Este esquema es sólo una aproximación al ámbito de los profesionales de la educación, pero pone de relieve su complejidad por la diversidad de funciones, de ámbitos, niveles y profesiones a que da lugar. Está realizado sobre la base de que el sistema educativo es más amplio que el sistema escolar, aunque en esta ocasión nos limitemos a este último.

Por lo tanto, en un sentido amplio se puede incluir entre los profesionales de la educación a todos los que se dedican, directa o indirectamente, a la docencia: los que imparten enseñanzas, los que dirigen o gestionan los centros educativos, los que supervisan o tiene cargos de asesoramiento, control y coordinación. Además debe hacer extensivo a ámbitos escolares o extraescolares, formales y no formales, sea cual sea el nivel o tipo de actividad. "En este sentido, se puede hablar de la profesión docente, lo cual nos permite incluir en ella tanto al maestro de primeras letras, como a los catedráticos y pedagogos de todo género" (Wanjiru, 1995, p. 232).

A nuestros efectos, centraremos la profesionalidad vinculada al campo educativo en la figura del profesor, con la advertencia de que con ella no se agota toda la profesionalidad educativa. En este sentido en que aquí lo estamos tratando, profesor es todo aquel que enseña de una manera organizada, en virtud de la preparación académica adquirida, que acredita a través de algún título, en alguno de los niveles del sistema escolar o estudio reglado. Esta tarea demanda de él otras actividades profesionales necesarias para cumplir el cometido fundamental. Entre ellas estarían la formación permanente, la investigación, el diagnóstico, la evaluación, el diseño curricular, la selección de valores, contenidos e instrumentos, etc.

\subsection{Heterogeneidad del colectivo docente}

Una primera observación acerca de la profesión docente es su heterogeneidad. Es difícil hablar de ella como un todo cuando en realidad está formada por miembros de diferentes niveles educativos y tipos de relación contractual: funcionario, interino, contratado laboral o administrativo. Cada uno de estos sectores tienen grados de formación, remuneraciones y culturas profesionales diferentes. En el nivel universitario y en el bachillerato, la especialización por materias y áreas de conocimiento se sobrepone a las obligaciones que como educador se supone que contrae todo profesor. En estos sectores, tradicionalmente ha primado mucho más el sentimiento de pertenencia a ámbitos disciplinares como la Física, la Historia, la Filología, etc., más que a la docencia. Suelen ser licenciados de diversas materias a las que se dedican de modo pedagógico (en su vertiente docente). Sin embargo, todos ellos son también profesionales de la enseñanza, puesto que se supone que su responsabilidad final es el desarrollo integral del sujeto y no sólo sus conocimientos en la materia. El creer que las funciones educativas se agotan en la transmisión de unos conocimientos que requieren un mayor dominio a medida que se asciende de nivel educativo, se ha traducido en una minusvaloración de la importancia de los problemas pedagógicos, que son en realidad los que permiten identificar a todo el colectivo, sin negar la especificidad que cada nivel plantea. 


\subsection{El profesor como profesional}

Como hemos indicado, centraremos la profesionalidad vinculada al campo educativo en la figura del profesor. Dejaremos de lado, pues, las figuras profesionales que no incluyen la docencia (entendida como "enseñanza" realizada sobre un grupo concreto de alumnos). Adviértase que la terminología no resulta baladí a la hora de analizar las implicaciones sociales que tiene respecto a la profesionalidad. Así lo consideraba el Consell Escolar de Catalunya en un documento sobre el tema:

"Existe una gran tradición en el ámbito educativo en la utilización de diversos términos para referirse a los profesionales. Prueba de ello son las palabras maestro, profesor, enseñante, docente, trabajador de la enseñanza..., que a menudo se utilizan indistintamente. Detrás de cada denominación puede esconderse una concepción diferente de la tarea, y tal vez del nivel de profesionalidad, con todas las implicaciones económicas, laborales y asociativas que ello supone" (1995, p. 79).

Nuevamente advertir que el empleo de la denominación "profesorado" no nos remite a los "profesionales de la docencia" sino a los profesionales de la educación, para dejar claras las implicaciones de índole moral que comporta, y la diversidad de tareas no estrictamente docentes que debe realizar el profesorado en tanto que profesional. La meta profesional de los profesores es, por lo tanto, la educación, aunque tal meta sea compartida con otros profesionales y con agentes educadores no profesionales; su especificidad consiste en lograrla incluyendo el dominio de los conocimientos curriculares que se vinculan con cada nivel educativo, y todo ello de acuerdo con una determinada manera de proceder, del mismo modo que se le exigen unas ciertas aptitudes y cualidades personales.

Haciendo una síntesis de varias propuestas más la propia reflexión, proponemos como características definitorias de la profesionalidad en las sociedades desarrolladas las siguientes (Sarramona, 1995):

1. Delimitación de un ámbito específico de actuación.

2. Preparación técnica y científica para resolver los problemas propios de su ámbito de actuación.

3. Compromiso de actualización y perfeccionamiento de los conocimientos y habilidades que le son propios.

4. Unos ciertos derechos sociales como individuo y como colectivo profesional.

5. Autonomía en la actuación.

6. Compromiso deontológico con la práctica docente.

A continuación desarrollaremos cada una de estas notas de la profesionalidad en general, advirtiendo su concreción en el campo de la educación, y desde la perspectiva del desarrollo profesional como un proceso de crecimiento personal y colectivo que ha de revertir en un mejor servicio a la sociedad.

\subsubsection{Delimitación de un campo propio de actuación}

Toda profesión acota un determinado campo de actuación, en el cual los profesionales se muestran habilidosos para resolver los problemas que allí surgen. La 
delimitación de tales campos tiene consecuencias laborales y legales para los profesionales respectivos, que pueden reivindicarlos como propios al tiempo que se les puede demandar responsabilidad en sus actuaciones sobre ellos. En algunas profesiones los campos están muy bien delimitados, en otras no tanto. En general resultan más difusos los campos de actuación referidos al ámbito social, donde los problemas y situaciones no son fácilmente objetivables, que los vinculados al mundo físico.

La educación pertenece a ese territorio donde los límites no resultan fácilmente objetivables. En primer lugar sabemos la complejidad misma de lo que conocemos como "educación", que no tiene interpretación unívoca, y en segundo lugar los problemas educativos no pueden ser controlados exclusivamente por los profesionales porque no actúan sobre ellos en solitario, de modo que su solución tampoco depende sólo de ellos. En consecuencia, dada la diversidad de concepciónes de lo que es educación, no existe unanimidad para valorar cuándo un problema "está resuelto". Creemos que no será necesario ejemplificar estas dificultades para que resulten bastante evidentes.

Estas consideraciones podrían llevar a la convicción de que no es posible hablar de profesionalidad en educación, por cuanto no existe un ámbito específico de actuación. No sería ésta nuestra opinión, por cuanto defenderemos que se puede delimitar qué significa educar en un marco institucional formal o no formal, aunque sí convendrá delimitar cuál es el papel de los agentes educadores no profesionales para así poder delimitar más claramente cuál ha de ser el grado de responsabilidad de cada uno de ellos y, por ende, el que corresponde a los profesionales.

En el documento citado del Consell Escolar de Catalunya se hizo una propuesta de delimitación de las actuaciones de los profesionales con respecto los restantes agentes educativos que inciden sobre la educación escolar, en especial los padres. Así se diferencian tres grandes bloques de actividad según el grado de incidencia del profesorado (1995, p. 82 ss.):

A) Ámbitos donde es preferente la actuación del profesorado. En primer término aparece cuanto hace referencia a la adquisición de una cultura básica mediante el curriculum escolar, con todo lo que entraña respecto a la consecución de los objetivos y contenidos propios de cada etapa escolar, así como lo vinculado con la socialización de acuerdo con los principios de la sociedad (democrática) vigente. La actuación profesional en este marco exige una serie de tareas diversas y complejas, como la planificación curricular, la adaptación del proceso pedagógico a las características y posibilidades de los educandos, el dominio de los recursos didácticos, la aplicación de técnicas de motivación personal, la dinamización del grupo clase, la evaluación, etc.

Las diferentes corrientes teóricas de la Pedagogía propondrán la manera concreta de materializar todas estas actividades, que sin duda tienen una perspectiva técnica pero cuyo peso en el conjunto no es unánimemente considerado; tampoco hará falta citar ejemplos de autores pertenecientes a uno u otro extremo. Sí habrá unanimidad en que, véase en perspectiva más técnica o véase en perspectiva más práctica, se trata de actuaciones que definen al profesional. Algunas con- 
cepciones que consideran al profesor como "mediador" entre el alumno y la cultura o bien como "facilitador" del aprendizaje deberán definir en qué consisten las actuaciones concretas para poder juzgar su pertinencia en tanto que profesional.

B) Ámbitos en que la actuación del profesorado es compartida con otras instancias. Aquí caben todas aquellas situaciones o metas educativas cuyo logro depende en gran medida del papel que jueguen otros agentes educadores, en especial la familia y el marco social próximo. Como ejemplos de estas situaciones podríamos citar:

La adquisición de ciertas actitudes y valores que se materializan especialmente fuera del marco escolar y que, en algunos casos, constituyen una de las opciones existentes en una sociedad pluralista y democrática. Se trata de aquellas metas educativas que demandan un compromiso previo de todos los agentes educativos implicados para realizar una actuación coherente y de mutuo refuerzo. A los profesionales les correspondería la aplicación de las técnicas pedagógicas más pertinentes, así como la determinación de cuáles debieran ser las actuaciones complementarias que debieran realizar los otros agentes educadores.

También es una actividad profesional compartida la que se refiere a propuestas que afectan directamente al libre futuro personal de los educandos, tal es el caso de la elección de materias optativas, de estudios profesionalizadores, de atención de anomalías físicas o psíquicas, etc. La actuación profesional en este apartado consistirá en la información y en propuestas orientadoras razonadas desde argumentaciones técnicas y experienciales, pero la decisión última deberá corresponder a los mismos educandos y sus familias, siendo compartido también el seguimiento de las consecuencias de la opción tomada.

C) Ámbitos en que la actuación y responsabilidad es solamente complementaria por parte del profesorado. Aquí cabrían toda una diversidad de opciones educativas en las que es claramente prioritaria la incidencia de la familia y del contexto inmediato: las creencias religiosas, la organización del tiempo libre, los hábitos de consumo, las preferencias artísticas, etc.

Se podrá decir que tiempo atrás la escuela tenía una influencia decisiva en estos aspectos, y así era en efecto. Pero en la actualidad las familias no tienen el mismo nivel de compromiso respecto las decisiones escolares, su nivel formativo es mayor, y tampoco existe el nivel de coincidencia sobre los modelos educativos a lograr que se daba antaño. Con todo, al profesorado le corresponde complementar la tarea de los padres y de otros agentes sociales en el desarrollo moral de sus alumnos, porque la libertad de conciencia, exige, primero su desarrollo.

En cualquier caso, no se puede perder de vista que esta propuesta de tres niveles de incidencia de la actuación profesionalizada del profesorado no tiene unos límites claros ni iguales para todo tipo de contexto social. Como se ha insistido reiteradamente, al tratar fenómenos educativos tratamos de fenómenos complejos, de modo que será preciso afrontarlos con perspectiva también compleja, superadora del empirismo comptiano (Lebert, 1995); sin olvidar que el profesor se encuentra muchas veces ante dilemas, más que ante problemas que tienen solución técnica (Gimeno, 1993; García Carrasco, 1996). En cada situación, pues, habrá que tomar las opciones pertinentes. Pero sí conviene tener claros cuáles son los 
límites de la actuación profesionalizada para clarificar cuál es el límite de la responsabilidad que se asume ante la sociedad, más en estos tiempos en que se tiende a verter sobre la escuela todo tipo de exigencias y responsabilidades.

\subsubsection{Preparación técnica y científica para resolver los problemas propios de su ámbito de actuación}

Característica altamente definitoria de las profesiones es una preparación específica para poder resolver las cuestiones que les son propias. Lo propio del profesional es la alta cualidad y eficacia del conocimiento que posee como "experto" y que al aplicarlo en la práctica puede solucionar los problemas sociales. En las actividades más profesionalizadas tales conocimientos se garantizan mediante el empleo de procedimientos científicos aceptados, otras se valen más de las reglas técnicas y de la generalización de la experiencia, otras se basan más en el dominio de destrezas y habilidades, como ocurre en las actividades artesanales, artísticas y deportivas.

Para el hombre actual la vida profesional supone estar en posesión de un saber asequible sólo a quienes dedican una parte de su vida a adquirirlo, a actualizarlo y a acrecentarlo. Es por ello que la propia evolución del concepto de ciencia y de su percepción social, afectan la delimitación del concepto de profesión, o al menos su clasificación jerárquica. Las profesiones que más avanzan según este criterio son aquellas que, mediante la investigación, la sistematización, la discusión pública, la innovación y la difusión de sus conocimientos, consiguen un cuerpo definido de problemas y de métodos para resolverlos.

La certificación académica o el título es un requisito exterior que acredita que quien lo posee domina los conocimientos especializados y necesarios para ejercer con garantías en ese campo de la actividad humana. Además, en ciertos ámbitos profesionales, junto a la titulación se exige la superación de concursos y pruebas de oposición, como es el caso del sector público.

Sin duda, cuanto más claramente definidos estén los ámbitos propios de actuación de una profesión más fácil resultará determinar el conjunto de conocimientos, habilidades y actitudes que debería constituir su formación inicial. Así en el caso del profesorado, que tiene que realizar una gran diversidad de actuaciones sobre las cuales no existe consenso social respecto el grado de responsabilidad que le corresponde, cuando existe una tradición arrastrada en ciertos niveles del sistema educativo según la cual "para enseñar lo más importante es conocer la materia", no extrañará que la formación inicial se mueva aún en un mar de indefiniciones. Solamente en los primeros niveles del sistema educativo (infantil y primaria), donde los objetivos informativos a lograr no son de mucho nivel, existe una clara formación pedagógica, aunque todos los indicadores manifiestan su insuficiencia para afrontar la complejidad de las tareas encomendadas (Esteve, Franco y Vera, 1995, p. 102). La educación secundaria sigue sin tener establecido el modelo que propugna la LOGSE de 1990, aun siendo claramente limitado en dar respuesta a las exigencias de este nivel educativo. Sobre la formación inicial para la docencia universitaria no son necesarios más comentarios. 
De manera rotunda hay que afirmar que es precisa una formación inicial específica que sea superadora de la consideración generalizada de que sólo el sentido común y la experiencia que proporciona el empirismo cotidiano son suficientes para acceder a la docencia (Torrents, 1995, p. 15). Más cuando resulta que el nivel y la claridad de la formación inicial de una profesión son factores que condicionan el prestigio social de la misma.

Ya hemos insistido en que la actividad desarrollada por el profesorado no es una simple actividad técnica, pero esto no significa que no haya una parte importante que sí lo sea, para la cual es precisa una preparación técnico-científica. Incluso la referencia que ya hemos hecho a la presencia de situaciones educativas de carácter dilémico permite establecer una diferenciación entre los "dilemas" técnicos, los dilemas ideológicos y los que tienen ambas vertientes. Por ejemplo, decidir el tipo de prueba a aplicar en una evaluación instructiva puede ser un dilema técnico, decidir si se aplica una sanción o no a un alumno en una situación determinada puede ser un dilema ideológico y decidir en qué idioma se va a iniciar la lectoescritura constituye un dilema técnico-ideológico.

En el ámbito educativo existe un conocimiento pedagógico especializado que es el que diferencia y confiere singularidad a la función docente. El mismo requiere un proceso de formación que permite obtener las bases iniciales para emitir juicios profesionales en cada situación, basados en la teoría, en el conocimiento experiencial y en la práctica. Es un conocimiento que radica en la capacidad para evaluar las situaciones educativas, analizar críticamente los factores de distinto tipo que las condicionan, elaborar estrategias de intervención, llevarlas a cabo y verificar los efectos producidos, sean deseables o no.

Una parte importante del conocimiento pedagógico especializado es de tipo científico y tecnológico porque no se agota en conocer, sino que pretende dirigir cursos de acción sistematizados (Colom, 1986; García Carrasco, 1988; Sarramona, 1990). Este aspecto tecnológico ha sido criticado aduciendo que conduce a un modelo profesional excesivamente especializado, fragmentado, supuestamente neutral y que descuida la dimensión ética de la enseñanza (Soder, 1991; Sáez, 1986). Sin embargo, como señala García Carrasco, el carácter tecnológico de la Pedagogía parece haber sido mal entendido cuando se le ha identificado con tecnologías mecanicistas o conductistas, haciendo un reduccionismo que confunde la parte por el todo. Así, lo que podría haber sido una crítica razonable a ciertas tecnologías, se ha convertido en el rechazo generalizado a uno de los ingredientes fundamentales del propio conocimiento pedagógico (Cfr. Vera, 1993).

Por otra parte, es indudable que los aspectos morales de la educación son fundamentales, pero como también lo son los componentes tecnológicos, ya que, como señala Sykes (1992) los profesores no pueden actuar moralmente si son técnicamente incompetentes o si no están provistos de los recursos necesarios.

Se ha confundido igualmente el pensamiento tecnológico con una organización tecnocrática de la enseñanza, en la cual se daría una excesiva fragmentación del trabajo de los profesores y una subordinación jerárquica a los técnicos de los niveles superiores que serían los que realmente tomarían las decisiones pedagógicas importantes. Sin embargo, más bien parece lo contrario: es la competencia 
profesional, incluidos sus aspectos científico-tecnológicos, la que permite incrementar las parcelas de autonomía de los profesionales docentes de cualquier nivel.

A ese conocimiento que otorga especificidad a la profesión docente, en los contextos escolares, se añade el dominio de los contenidos (conocimientos, procedimientos, actitudes y valores), como uno de los elementos que han de ser tratados pedagógicamente para convertirlos en ingredientes capaces de producir aprendizajes educativos. Han de ser llenados de significado social, cultural y personal; y han de ser secuencializados, temporalizados, ejemplificados y practicados en función de los alumnos y la situación.

Otro tema, siempre polémico y complicado de resolver pero de importancia indudable, es el referente a las características personales que debieran exigirse a los profesionales de la educación y más concretamente al profesorado. Unas palabras de Pilar Benejam escritas hace más de diez años son sumamente ilustrativas al respecto: "Aunque la selección de los candidatos ofrezca dificultades eso no invalida el hecho de que haya maestros más capaces que otros, y si creemos que el Magisterio es socialmente importante, es preciso aplicar la selección más adecuada y menos mala posible, con el fin de dar las pocas plazas disponibles a los candidatos que tienen más posibilidades de resultar idóneos" (1986, pp. 61-63).

El mensaje consiste en afirmar que para esta profesión, como ocurre en cualquier otra, todo el mundo no sirve. Fácilmente estaremos de acuerdo en que cualidades personales como la paciencia, la apertura de ideas, el compromiso personal respecto los valores que se quieren fomentar, el sentido de justicia, etc. son consubstanciales a la profesión docente. No está claro, sin embargo, que las cualidades personales que resultan eficaces en la enseñanza sean las mismas en todas las situaciones educativas. Muchas investigaciones se han encargado de rebatir, desde hace ya décadas, los supuestos del paradigma presagio-producto. En cambio sí está comprobado que hay un porcentaje de profesores que acceden a la profesión con patologías psicológicas no resueltas que pueden poner en peligro su salud mental y la calidad de su enseñanza. Por ello, parece aconsejable introducir mecanismos de selección para detectar estos problemas y darles solución, si la tienen, antes del ejercicio de la profesión. El problema es que estas medidas deberían aplicarse simultáneamente a muchas profesiones (psicólogos, médicos, pilotos, jueces, etc.), porque de lo contrario se corre el riesgo de estigmatizar al colectivo que las promueva en solitario (Cfr. Esteve, 1987; Vera, 1988a; Esteve, Franco y Vera, 1995).

\subsubsection{Compromiso de actualización y perfeccionamiento de los conocimientos y} habilidades que le son propios

Poco habrá que insistir para sentar la exigencia de la actualización y perfeccionamiento de los conocimientos y habilidades profesionales cuando estamos situados en unos tiempos históricos de permanente cambio y evolución. La formación permanente se une así a la experiencia reflexionada para lograr el desarrollo profesional. Pero ambas dimensiones no son ajenas a la formación inicial comentada anteriormente. 
Dejando ahora de lado el hecho de que en algunos casos la denominada "formación permanente" del profesorado se erige en auténtica formación inicial por el hecho de no haber existido ésta o haber resultado totalmente insuficiente, el caso es que la formación inicial resulta ser un fuerte condicionante para la actitud general con que se afronta la profesión y, consiguientemente, incide sobre la capacidad de optimización de la formación permanente y la misma experiencia acumulada, que en ningún caso puede ser contemplada como un simple encadenamiento de ensayo-error.

La LOGSE señala en su artículo 56.2 que «la formación permanente constituye un derecho y una obligación de todo el profesorado y una responsabilidad de las Administraciones educativas y de los propios centros". Desde hace unos años, y especialmente con motivo de la aplicación de la Reforma del sistema educativo, se han prodigado los programas de formación permanente, hasta el punto que ya constituyen una tradición fuertemente arraigada en algunos lugares; con sólo nombrar los centros de profesores y las "escuelas de verano" se evoca toda una línea de acción al respecto.

No obstante, la formación permanente del profesorado se mueve en una cierta ambigüedad respecto al nivel de compromiso que corresponde al interesado y al titular del centro escolar, sea éste de naturaleza pública o privada. Ello ocurre porque el profesorado tiene por un lado características de profesional liberal, tal es el caso de gozar de una cierta autonomía de acción, y por otro resulta ser un asalariado. De acuerdo con la primera perspectiva la formación permanente debiera corresponder a su entera iniciativa, mientras que de acuerdo con la segunda sería responsabilidad de la parte contratante. En el documento ya citado del Consell Escolar de Catalunya (1995) se dice al respecto:

"... entendemos que la formación, si se tiene en cuenta que el objetivo último es la mejora de la práctica docente, corresponde básicamente a la iniciativa personal de cada profesional, mediante la asistencia a cursos, conferencias, congresos, consulta bibliográfica, etc. sin olvidar la innovación e investigación dentro del aula" (p. 94).

Por otra parte, la competencia educativa no es algo estático, definitivo y completamente estandarizado y universalizable, sino un bagaje previo y necesario, que permite afrontar la heterogeneidad y complejidad de las situaciones educativas. Por ello es importante que el docente tenga una actitud indagadora e innovadora que le permita ver su trabajo como una serie de problemas a resolver desde su conocimiento actual, pero a través del cual se puede generar nuevo conocimiento. Con esto queremos resaltar el carácter de formación permanente que incorpora la acción educativa cuando se afronta con una actitud investigadora realizada, fundamentalmente, en equipo. Ello sólo es posible desde una buena formación inicial, porque de lo contrario el proceso práctico será puramente artesanal. La forma de ejercer la profesión es también un modo de aprendizaje que o bien impulsa, o bien frena, el proceso de profesionalización. Más que ser o no profesionales, de una vez y para siempre, avanzamos o retrocedemos en ese proceso (Imbernón, 1994, p. 28).

Otra cuestión es cómo se vincula la formación permanente o, mejor dicho, el perfeccionamiento profesional que cabe esperar de ella con la promoción. Medi- 
das que vinculen automáticamente la formación con la promoción sin que no medie ningún tipo de evaluación sobre la eficacia de la primera, tal como se ha establecido en nuestro contexto, constituye una perversión de la formación misma, que entonces puede ser vista como un simple requisito administrativo para lograr aumentos salariales. Otra consecuencia ha sido la prodigalidad de cursos convencionales y de actividades formativas que no siempre coinciden con las necesidades reales del sistema (Marcelo, 1996).

\subsubsection{Unos ciertos derechos sociales como individuo y como colectivo profesional}

Es evidente el carácter de "delimitación del territorio" dentro del cual ejercen con plena competencia las profesiones y que les permite negar su entrada a los "intrusos". Este reconocimiento del derecho a ejercer en un ámbito social determinado, para lo cual se exige la "venia" del poder establecido, le da a la profesión un carácter político, tal como destacan autores como Popkewitz (1990), quien subraya el aspecto de enmascaramiento de estructura sociopolítica que delata la situación de las profesiones. Ginsburg (1988) estudia cómo en Estados Unidos y en algunos países europeos la fuerza de determinados grupos profesionales ha ido paralela a los grandes cambios económicos, que han hecho necesario el restablecimiento de la "armonía social" a través de su encauzamiento por medio de unas organizaciones a las que se le dan funciones, prestigio y un poder limitado. Y ahí está la contradicción entre la autonomía del poder político y su dependencia del mismo para mantener su status y funciones.

Este privilegio de las corporaciones en la época en que el poder del Estado ha sido débil, ha dado un poder exorbitante a las profesiones "liberales", desde que apareció en Inglaterra el Estado del "laissez faire, laissez passer", y ha permanecido largamente abierto para las nuevas actividades, en los países anglosajones, en los que el Estado ha dejado el campo libre al control parcial de los grupos profesionales. En los otros países donde la actividad social ha estado más estrechamente controlada por un poder central, el Estado o la Iglesia, las actividades han tenido más difícil el establecerse como profesión.

En este aspecto la actividad docente ha quedado en una posición ambigua. Con todo habrá que diferenciar entre los derechos sociales que corresponden a la profesión y la imagen social de la misma.

El carácter de monopolio para enseñar en el caso de los maestros españoles nos lo describe Luzuriaga (1916) al relatar cómo los futuros maestros aprendían el oficio junto a un maestro experimentado, lo cual dió lugar a la aparición (efímera) de una "cátedra normal", y posteriormente a la creación de Instituciones de fundación Real como la Hermandad de San Casiano (1642) y el Colegio de Primeras Letras (1780), que tenían atribuciones para examinar, y por tanto, para otorgar las prerrogativas para ejercer la profesión. Después de la creación de las Escuelas Normales (1839) y la Inspección (1843) la función formativa y controladora quedaba establecida.

Actualmente se determina legalmente que hay que poseer una titulación específica para ejercer la profesión docente. La LOGSE determina de manera taxati- 
va (art. 16) que solamente los titulados como maestros de primaria podrán ejercer la docencia en este nivel educativo, mientras que para ser profesor de secundaria será preciso ser licenciado, ingeniero, arquitecto o título equivalente, además de poseer el "título profesional de especialización didáctica" (art. 24).

Sin embargo, la imagen social no es paralela al citado reconocimiento legal. Se puede afirmar sin exageraciones que en estos tiempos se advierte una actitud crítica generalizada hacia el profesorado y hacia la escuela como institución, pese a existir una valoración alta de la importancia que ambos tienen en el futuro de la sociedad. Diversas explicaciones se pueden dar a esta baja consideración social.

Una primera explicación se puede encontrar en el hecho, ya comentado, de que la educación no es una actividad monopolizada por los profesionales, sino que nos implica a todos. Otra es el aumento general de la cultura de la población, que lleva a relativizar el nivel cultural de los docentes. Otra, el rompimiento de la unidad de criterios sobre qué ha de ser una buena educación, reflejo del pluralismo cultural e ideológico que caracteriza la sociedad contemporánea. Todo ello se concreta en la comentada falta de prestigio social. El Consejo Escolar de Euskadi (1995) aún añade lo siguiente:

"La crisis de valores en que vive la sociedad, los cambios de la organización social y familiar, los nuevos estilos de vida, las situaciones de desestructuración e incluso de marginación en que vive un número creciente de alumnos y alumnas, conduce a unas conductas que hacen cada vez más difícil la integración escolar, el esfuerzo en el estudio y, en general, la actividad escolar" (p. 140).

$\mathrm{Al}$ igual que otros profesionales, como médicos, jueces, investigadores, etc., el profesor ha sufrido una erosión de su autoridad intelectual relacionada con el proceso de relativización del valor del conocimiento científico, en particular, y del conocimiento, en general. Desde Nietzsche, la teoría del conocimiento, ha supuesto una crítica del esencialismo que implica la creencia de la "cosa en sín, y su sustitución por simples interpretaciones que no son sino proposiciones de significado. De ahí se ha pasado a la pretendida igualación de todas las interpretaciones, con independencia de que estén basadas en la superstición, el capricho, la moda, o en argumentos y datos contrastables. También ha sufrido una merma la autoridad moral del profesor, por la coexistencia plural de modos de vida y una socialización divergente, donde los modelos contradictorios parecen anularse unos a otros, produciendo una cierta sensación de caos en la que es difícil redefinir la tarea de educar.

Si en el pasado el conocimiento se repartía como un bien escaso entre la población, si además se tenía menos escepticismo respecto al concepto de verdad, lo bueno y lo bello, era lógico que aquella relación se estableciese sobre la base de cierta veneración, respeto, reconocimiento, e incluso idealización de la autoridad del profesor. Ahora el profesor ha de ganarse el reconocimiento social, teniendo en cuenta que el saber está más repartido; que la verdad, lo bueno y lo bello son interpretados como productos humanos, condicionados social y culturalmente, y sujetos a la discusión pública; que además han surgido unos poderosos competidores en la tarea de difusión del saber, de las interpretaciones del mundo, y de la creación de actitudes y valores, como son los medios de comunicación social 
y las nuevas tecnologías. Todos estos procesos de cambio no hacen sino evidenciar la necesidad de una mejor formación pedagógica, intelectual y moral de los profesores que refuerce su papel de intelectual crítico y la caducidad del modelo de simple transmisor de conocimientos.

Por otra parte, en los años 60/70 dos corrientes que han contribuido a la pérdida de prestigio de los docentes son: las teorías sociológicas fatalistas, que les han acusado de ser agentes de la reproducción de las desigualdades sociales, y los movimientos de desescolarización. Sin embargo, la socialización que realiza hoy el profesor se da en un marco de fuerzas divergentes y de pública discusión de conocimientos, procedimientos y valores, de modo que la función de estabilidad social que realiza la educación, ya no se da por la vía de la reproducción mecánica. Diversos estudios sociológicos nos muestran "que la posición social se hereda hoy menos que ayer, es decir, que las sociedades son cada vez más meritocráticas y menos adscriptivas" (Gil, 1996, p. 91). Igualmente se observa que los títulos académicos no garantizan la ocupación, aunque capacitan para desempeñar varios trabajos no necesariamente relacionados con los contenidos estudiados. Con estos parámetros, sin ocultar las evidentes desigualdades sociales, no está clara la labor de reproducción social por medio de la selección según el origen social.

Asimismo las reformas de los años 80/90, enmarcadas en una lógica racionalista que separa teoría y práctica, no han hecho más que subrayar la paradoja de valorar por una parte a los "expertos" y descalificar los saberes y el trabajo de los docentes. Popkewitz (1990) señala cómo hoy, por una parte, el tema de la profesionalización está a la orden del día, se elogia la autonomía y capacidad de reflexión de los docentes y las políticas descentralizadoras parecen confiar en la pericia de los docentes; pero, a la vez, las reformas educativas, a fin de mejorar la calidad y eficacia de los sistemas de enseñanza han llamado a sus expertos que se supone controlarán y evaluarán los procesos escolares y la actividad de los docentes.

Hargreaves (1992) señala cómo la emergencia de la tutela científico-curricular sobre los docentes se acompaña frecuentemente de la intensificación de su trabajo. Esta intensificación es un argumento en favor de la necesidad de su profesionalización, sin embargo se convierte en un elemento desprofesionalizador cuando este aumento de funciones no va acompañado de mejoras en la formación, en las condiciones de trabajo, en sus competencias; en definitiva, cuando el incremento no va acompañado de unas mejoras de las condiciones laborales, condenando a los profesores a hacer mal su trabajo.

Liston y Zleichner (1993) han demostrado claramente cómo dichas estrategias reformadoras han desembocado en un control más fuerte de los contenidos, los procesos y los resultados del trabajo escolar que conducen a una fuerte burocratización.

King (1994), examinando el programa de certificación del National Board for Professional Teaching Standars (NBPTS), centrado en la profesionalización, considera que el último programa confeccionado contiene demasiados controles para los profesores, lo cual además de aumentar la distancia entre los profesionales y las personas no expertas, inhibe la colaboración entre el personal de la escuela. 
Esta contradicción marca la situación de los docentes de nuestros días que son vistos, por una parte, como profesionales poco cualificados, y por otra, como depositarios de las esperanzas de cambio social y cultural (Esteve, Franco y Vera, 1995). Evidentemente, la crítica social no afecta exclusivamente a la profesión docente, sino que también la sufren otras muchas profesiones, pero en nuestro caso, además de las causas indicadas, los autores suelen añadir otras, como las siguientes:

- El amplio volumen del colectivo hace muy difícil que pueda conseguir condiciones sociales ventajosas. Hay que señalar que actualmente existe un salario (en el sector público) que curiosamente es bastante superior al que cree el conjunto de la población. En un estudio encargado en 1994 por el Departament d'Ensenyament de la Generalitat de Catalunya, sólo un 1\%, en el caso de primaria, y un $1,5 \%$ en el de secundaria, de los encuestados eligieron la opción salarial que se corresponde con la más común en la realidad (Departament d'Ensenyament, 1994, pp. 37-39)

- El origen social del colectivo, en su mayoría procedente de la clase baja y media baja, aunque no existe uniformidad al respecto. Hay distintos grupos de profesores con diferente formación, titulación, salario, prestigio y oportunidades de promoción. Los niveles de enseñanza media y superior reclutan sus efectivos en los estratos más altos de la clase media en mayor medida que los de la enseñanza preescolar y primaria. Entre hombres y mujeres, éstas tienden a proceder de posiciones sociales más altas (Gil, 1996, pp. 53-60).

- En cuanto al prestigio social, los funcionarios docentes de universidad y los directivos de centros de secundaria, es decir, en torno a un diez por ciento de todo el profesorado, estaría en el estrato superior, junto a los gerentes, directivos y profesionales liberales. El resto del profesorado, el noventa por ciento, estaría en un segundo nivel junto a técnicos y empleados medios, más en función de la valoración social de la educación, que de las retribuciones, ya que en este caso se bajaría al tercer nivel junto a administrativos y trabajadores de servicios (Fernández Enguita, 1990, p. 162).

- La proporción de mujeres que forman parte de la profesión docente son ampliamente mayoritarias en los niveles de preescolar y primaria, se equilibra en secundaria y es menor en la universidad, aunque en este último nivel existen profundas diferencias según las carreras. Entre las razones que parecen explicar este fenómeno se pueden destacar las siguientes:

1. La enseñanza es una actividad extradoméstica que ha sido socialmente considerada muy apropiada para la mujer en su prolongación del papel de madre.

2. Los bajos salarios que, a igual titulación, ha ofrecido el magisterio, comparados con sectores del comercio, la industria o la propia Administración, ha disuadido a parte de los hombres y no a las mujeres.

3. La sociedad patriarcal ha considerado tradicionalmente que la enseñanza era compatible con el cuidado de los hijos, que el salario de la mujer era necesariamente complementario al del hombre y que, en cualquier caso, el trabajo de la mujer en la enseñanza podía tener un carácter transitorio en caso de que se casase con alguien de una posición superior. 
4. Las mujeres han provenido de familias de clase media más elevada, que han enviado a los varones a estudios con más valor de mercado, reservando la enseñanza para las hijas.

5. Con todo, una de las razones más poderosas para explicar la feminización de la enseñanza, es que la escuela era casi la única actividad profesional a la que podía dedicarse la mujer española a finales del XIX, ya que tenía vetada la entrada en la universidad. Esto explica también por qué las profesoras han provenido de clases sociales más elevadas que los profesores. De hecho, el proceso de feminización en España no se inicia hasta 1970, hace tan sólo cerca de tres décadas, coincidiendo con la implantación de la coeducación. En cambio, en los países anglófonos como Inglaterra, Gales y los Estados Unidos acusan este fenómeno desde finales del XIX, porque allí, desde esa época había coeducación. La coeducación abrió el acceso de la mujer a todos los centros escolares (Sanchidrián, 1996 y Apple, 1989).

Se insiste por parte de los sociólogos que la tradición patriarcal y discriminatoria para las mujeres lleva al desprestigio de una profesión cuando es mayoritariamente femenina (Borja, 1990). La feminización ha sido probablemente uno de los factores del bajo prestigio social de los docentes, no porque ellas estuvieran peor preparadas, sino porque socialmente no se les ha reconocido su buena capacidad profesional en la misma medida que a los hombres. La enseñanza ha compartido la misma suerte que las mujeres: baja estima social, importancia secundaria del sueldo, reconocimiento de la entrega y la abnegación pero no de las aptitudes profesionales, subordinación más que autonomía, aprecio por sus buenas costumbres pero desconfianza de su juicio crítico, etc., con todas las consecuencias directas sobre los procesos de formación, promoción e imagen social.

- El nivel de las titulaciones académicas que permiten el acceso a la docencia, en el caso de los primeros niveles del sistema educativo, son de grado medio y, en muchos países, además, están fuera de la universidad. En el caso de la enseñanza media, como ya se ha indicado, no existe una carrera profesional específica y la docencia constituye para muchos de los profesores de este nivel una salida de "segunda fila" ante la imposibilidad de haber logrado un puesto profesional acorde con su titulación específica.

- El tipo de acción profesional, dirigida mayoritariamente a niños y adolescentes para quienes la asistencia a la escuela es obligatoria, ha supuesto, de hecho, ejercer funciones de "guardería" en una sociedad donde los padres tienen organizada su vida de manera que no pueden atender suficientemente a sus hijos. Esto ha hecho más visibles las dotes de paciencia, comprensión y afecto hacia los alumnos que las propias competencias profesionales.

- La existencia de múltiples agentes, no escolares, con influencia configuradora que disponen de las más avanzadas fuentes informativas, ha relativizado el impacto formativo de las agencias tradicionales de educación como la escuela. Actualmente el profesorado se ve obligado a competir con el poder persuasivo de esos agentes pertrechados de medios tecnológicos, en una batalla desigual dada la lentitud con la que se toman las decisiones políticas en lo que afecta al sistema escolar. 
Todo este conjunto de factores explica esa situación difícil que afronta el profesorado, resumida así por Esteve, Franco y Vera (1995):

"Mientras que hace veinte años, los padres estaban dispuestos a apoyar al sistema de enseñanza y a los profesores ante las dificultades del proceso de aprendizaje y de la educación de sus hijos, en el momento actual encontramos una defensa incondicional de los alumnos, sea cual sea el conflicto y sea cual sea la razón que asista al profesor" (pp. 32-33).

\subsubsection{Autonomía en la actuación}

El principio de libertad subraya el margen de autonomía con el que aspira a realizarse el trabajo del profesional en su relación con el cliente, con quien contrae una responsabilidad personal difícilmente delegable. A diferencia de otros colectivos de trabajadores, los profesionales liberales son plenamente autónomos en su trabajo, no teniendo que someterse a una regulación ajena.

Puesto que al profesional se le supone experto en su ámbito de competencia, sólo aquellos que están en posesión de igual conocimiento, es decir, sus colegas, pueden tener criterio válido sobre la forma de ejercer la profesión. Por ello, el profesional ha de ser autónomo en sus decisiones, al margen de las presiones procedentes de sus clientes o de quienes no son miembros de la profesión. El profesional y sus colegas se hacen responsables de las consecuencias de sus decisiones, porque se supone que tienen los conocimientos que les permiten tomar, en cada momento, la decisión adecuada dentro de los límites de sus competencias.

Sin embargo, esta característica que fue muy importante en el desarrollo histórico de las profesiones, es hoy una de las más controvertidas, ya que numerosos profesionales que tienen reconocidas las mismas competencias y derechos que sus colegas en ejercicio liberal, trabajan como asalariados para organizaciones públicas o privadas, y muchos de ellos comparten su responsabilidad ante el cliente con otros profesionales o con instancias burocráticas, bajo un mayor o menor control del Estado o de otras instancias administrativas. Con todo, su gran capacidad de influencia sobre el poder político, les permite intervenir o condicionar la regulación legal de su actividad y las normas a las que han de someterse. Los ejemplos clásicos son los médicos, abogados y arquitectos (Fernández Enguita, 1990, p. 149).

De hecho, el papel de los servicios públicos no significa necesariamente una restricción de la libertad profesional, siempre y cuando puedan disponer de medios suficientes para prestar sus servicios en mejores condiciones o en colaboración con otros profesionales. La complejidad de la vida moderna y la universalización de los derechos a toda la población han hecho necesario organizar los servicios de salud, por medio de una red de centros muy lejos de la consulta privada, y lo mismo ha ocurrido con los bufetes de abogados o con la enseñanza, en la que los antiguos preceptores han devenido en docentes asalariados. Si bien es cierto que las antiguas profesiones, al menos en una parte importante, se han ido convirtiendo en empresas de servicios, no lo es menos el carácter profesional que intentan imprimir las empresas y los comercios a sus relaciones con el cliente (Martín-Moreno y De Miguel, 1982, pp. 37-39). 
Históricamente, el fin del siglo XVIII representa un período clave en la historia de la educación y de la profesión docente. Como afirma Novoa (1994), "la formación de los enseñantes es solidaria de la consolidación de los Estados-Nación en el cuadro del proyecto iluminista que ha asegurado la transición del antiguo Régimen". Los docentes fueron el mejor instrumento para la instauración del nuevo orden social del cual se convirtieron en "instituteurs". Sobre este punto también insiste Luhmann (1993, p. 62), cuando señala que la exigencia de autonomía para la praxis profesional de la enseñanza se produce al mismo tiempo que la diferenciación del sistema educativo respecto al religioso.

Así pues, la profesionalización de los docentes está íntimamente ligada a la formación de los Estados Modernos. Esta vinculación les asegura la protección y el prestigio deseados, pero a expensas de una pérdida de una mayor autonomía profesional.

La ambigüedad del status está claramente expresada en este texto de Novoa (Ibíd.) "...los enseñantes se encuentran siempre "entre" dos mundos, "entre" dos universos; no son ni pueblo ni burguesía; deben poseer algunos conocimientos, pero no deben en ningún caso pretender ser unos intelectuales; gozan de una considerable autonomía en la conducción de la clase, pero toda regulación autónoma de la profesión les está vedada, se considera que ejercen una influencia sobre las comunidades, pero se mantienen modestos y evitan toda preeminencia o notoriedad social; deben percibir un salario justo para llevar una vida digna siendo tan condenable que se presente miserable como el que manifieste riqueza...".

El docente es celoso de este principio de autonomía, puesto que ve su actividad como exclusivamente propia, de modo que "una intromisión-ya sea de la burocracia cultural, de la opinión pública local o de los padres de familia- le parece algo ajeno a la materia, tal como señala Luhmann $(1993$, p. 65), y este mismo autor añade que incluso las reformas curriculares actualmente parecen caer en esa zona de rechazo, este glacis de la autonomía profesional" (Ibídem).

En nuestro contexto, la autonomía de acción que corresponde al profesorado se sitúa en el marco más amplio de la denominada libertad de enseñanza. Según sentencia del Tribunal Constitucional (13/2/81), la libertad de enseñanza se entiende como una proyección de la libertad ideológica y religiosa (de padres, alumnos y profesores) y el derecho a difundir libremente los pensamientos, ideas y opiniones que garantizan otros preceptos constitucionales; entre estos derechos está la libertad de cátedra por lo que se refiere al profesorado. Pero, ¿cuál es el contenido de este derecho profesional?

En principio, se podría advertir una cierta contradicción entre el hecho de reconocer capacidad de autonomía de acción al profesorado, al estilo de los profesionales liberales, cuando en realidad se trata de profesionales asalariados, sea de la Administración, sea de un organismo privado; y sin duda que esto provoca en ocasiones confrontación de intereses.

Aunque no ha sido desarrollada reglamentariamente, hay sentencias aclaratorias del Tribunal Constitucional que sitúan la libertad de cátedra en los límites que enmarcan las finalidades del sistema educativo, los derechos que tienen los restantes miembros de la comunidad educativa, el proyecto educativo propio de cada 
centro y las normativas específicas que fijan los mínimos curriculares, los horarios y las condiciones laborales. De estos límites ha sido motivo de litigio en más de una ocasión la posible confrontación entre la libertad de cátedra y el proyecto educativo del centro, que en los de los centros privados se vincula con su ideario.

En principio, "una actividad docente hostil o contraria al ideario del centro puede ser causa legítima de despido" (Llamazares, 1995, p. 54). Pero el respeto al ideario, tal como reconoce la citada sentencia del Tribunal Constitucional, tampoco puede traducirse en una obligación por parte del profesorado de "convertirse en apologista del mismo, ni transformar la enseñanza en propaganda o adoctrinamiento, ni subordinar a este ideario las exigencias que el rigor científico impone".

Algunos autores se preguntan qué margen queda realmente para la libertad de cátedra después de las limitaciones que marca la misma ley que la reconoce. Pero la realidad es que quedan amplios márgenes para ejercer la autonomía de acción, tal como reconoce Gimeno (1993, p. 65) cuando afirma textualmente que "quedan espacios y esperanzas para la acción" y luego añade que "tan irreal es la imagen del profesor completamente autónomo como el creer que sus respuestas son acciones meramente adaptativas a las situaciones recibidas" (Ibídem). No se puede negar que, como reconocen otros autores, «una vez se cierra la puerta del aula, el profesor goza de considerable libertad de acción" (Fernández Enguita, 1993).

Sin duda existen razones científicas y técnicas de la profesión que avalan esta necesidad de autonomía de acción en la actividad docente. En primer lugar es evidente que los conocimientos científicos y las normas de acción que pueden elegirse para interpretar y actuar sobre un fenómeno educativo no son únicas, de modo que muchas veces es preciso elegir o combinar varias opciones posibles. Ello sin olvidar las preferencias y aptitudes personales del docente que por esto mismo harán más eficaz una opción que otra. Por otra parte, la misma normativa legal que determina mínimos curriculares y principios organizativos se deberá adaptar a la realidad concreta de cada caso y contexto social que envuelve al centro.

Sólo una advertencia cabe a esta libertad de elección científica y metodológica: no puede llevarse a cabo desde el desconocimiento de la cultura profesional compartida y ha de situarse en el marco de las tareas colectivas que supone la institución escolar. La libertad de acción profesional ha de ser siempre una expresión de la reflexión individual y colectiva, permitiendo la acción coordinada sobre los alumnos, al tiempo que potencie la capacidad de investigación y de innovación dentro de la profesión. No hará falta insistir que la libertad de acción o de cátedra no puede ir en contra de los conocimientos científicos consolidados ni en contra de los derechos que asisten a los educandos, sus familias y la sociedad en su conjunto. Como señala el Consell Escolar de Catalunya, "la actuación autónoma del colectivo profesional ha de estar siempre al servicio de los educandos, y no utilizarla como protección corporativista" (1995, p. 16). En este último sentido, la libertad de cátedra se vincula con la conciencia ética del profesorado, a la cual nos referiremos a continuación. 


\subsubsection{Compromiso deontológico con la práctica docente}

A los profesionales no les basta con estar sujetos a las leyes, sino que establecen mecanismos internos para controlar su actividad, de modo que sean predecibles sus relaciones con los clientes y se cumplan ciertos deberes. Aparte del compromiso social que implica, el código refuerza el carácter noble y vocacional de la actividad, lo que no quiere decir que necesariamente se vaya a cumplir.

El código deontológico es otro de los elementos controvertidos dentro de las profesiones actuales, debido a la dificultad de encontrar un consenso en torno a unas normas morales que sean aceptables por todos los miembros del colectivo, independientemente de sus creencias o tendencias personales, sobre todo cuando éstas tienen consecuencias en su vida extraprofesional. Pensemos por ejemplo en cuestiones tan controvertidas como el aborto o la eutanasia en el caso de la sanidad.

Muchas profesiones disponen de un código ético en el que se resumen las obligaciones derivadas de las características que estamos viendo. No es necesario que ese código esté escrito. Es suficiente con que esté sancionado por la tradición y la presión del grupo y oriente la conducta de los miembros del colectivo.

Todas las profesiones tienen su propia deontología, de acuerdo con la cual rigen su comportamiento individual y colectivamente. Unas ya tienen una larga tradición al respecto, otras se han preocupado recientemente del tema, a tenor de los cambios sociales vividos. Como ejemplos podemos poner la larga tradición de los médicos que, sin embargo, en 1997 han abierto un debate interno para actualizar su código deontológico y los periodistas, que en diciembre de 1992 elaboraron el suyo en Barcelona.

No hay duda que la propuesta de un código deontológico por parte de un colectivo profesional es indicativo de un compromiso social y fruto de un debate interno, aun cuando siempre exista el riesgo de que se quede en un mero formalismo y que el colectivo en cuestión no tenga mecanismos internos para velar por su cumplimiento. La cuestión de fondo seguramente está en la fuerza que pueda tener el código en cuestión en unos tiempos de relativismo moral generalizado, en tiempos postmodernos donde "el narcisismo trasciende el simple egocentrismo" y nos encontramos ante "una personalidad donde la autoestima se plasma en una autoindulgencia y una autoimportancia sin límites", como señala Hargreaves (1996b, p. 102).

La profesión docente tiene una indudable dimensión moral no sólo porque actúa sobre las personas, sino porque lo hace precisamente sobre su misma dimensión moral, ya que pretende su bien de manera íntegra. Una deontología profesional supone, pues, asumir la responsabilidad de las propias acciones, siempre bajo la perspectiva que han de ir encaminadas al bien del educando. La deontología trata de los deberes profesionales con respecto a las personas y a la comunidad a la que se sirve, deberes que se integrarán con los derechos que también corresponden al profesional.

Hoy por hoy no existe entre nosotros un código deontológico que haya sido asumido por el conjunto de la profesión docente, si bien existen propuestas bas- 
tante elaboradas del mismo, entre las cuales cabe citar la del Consejo General de Colegios Oficiales de Doctores y Licenciados en Filosofía y Letras y Ciencias (1994), el propuesto por el Consell Escolar de Catalunya (1993) y el código deontológico que forma parte del Estatuto del Pedagogo, aprobado en Valdepeñas por la Asamblea de Pedagogos en 1986 y que afecta a los especialistas en Ciencias de la Educación (Moratinos, 1989). Pareciera sin embargo que ésta es aún una tarea pendiente que pudiera contribuir al deseado aumento de prestigio de la profesión, si bien no parece fácil lograr el necesario consenso entre todos los implicados.

La complejidad e integridad de la actuación profesional del profesorado nos podría llevar fácilmente a demandar que los docentes fueran personas moralmente perfectas, que sintetizaran todas las virtudes posibles, lo cual ciertamente no es realista ni posible. Pero también resulta evidente que no se puede educar en unos valores que no se comparten, de modo que sí resulta éticamente exigible al profesorado que comparta los valores que socialmente son comunes en una sociedad democrática que busca la mejora individual y colectiva, aunque el profesor como persona se adhiera a una opción concreta de las vigentes en el pluralismo característico de las democracias actuales. Si no se puede pedir la perfección moral, sí parece lógico pedir una predisposición para trabajar en beneficio de los destinatarios de la acción educativa, por encima de los intereses y creencias personales. La honestidad profesional no consistirá tanto en ser "transparente" respecto al propio yo, cuanto en favorecer la libertad y el desarrollo integral de los educandos. Un texto de Trilla (1992) resulta muy contundente al respecto:

“... la función profesional del educador no es prioritariamente la de transmitir sus propias opciones o creencias religiosas, ideológicas o políticas. Con lo cual no estamos diciendo que la transmisión de las mismas le esté necesariamente vedada en su ejercicio profesional, sino simplemente que la tarea que social y profesionalmente le define no es ésta; para expresarlo de manera muy prosaica pero más explícita: al maestro no se le paga para que inculque a los educandos sus personales opciones ideológicas" (p. 51).

\section{SOCIALIZACIÓN PROFESIONAL Y ASOCIACIONES PROFESIONALES}

La socialización es el proceso por el cual las personas adquieren los valores, actitudes, intereses, capacidades y saberes; en resumen, la cultura que está en vigor en los grupos en los que pretenden integrarse como miembro. Si nos centramos en el terreno de las profesiones, suele diferenciarse el concepto de socialización profesional del concepto de formación. La formación es un proceso institucionalizado y explícito de adquisición de saberes y la socialización en cambio es un proceso frecuentemente informal de adaptación que dura más largo tiempo.

Los diferentes modelos teóricos que explican este proceso de socialización son el funcionalista, el interaccionismo simbólico y la sociología crítica y conflictualista, que han dado lugar respectivamente a los diferentes modelos de formación de profesores: tecnológicos, críticos (Stenhouse, Carr y Kemmis, Zeichner...) y del profesional reflexivo (Schön). A partir de todos ellos surgen diferentes propuestas para lograr una socialización y formación profesional del docente. 
Para la corriente funcionalista será la planificación de la adaptación a los comportamientos declarados como correctos y a través de un proceso de imitación y aprendizaje.

Para la corriente crítica, ante un mundo en conflicto y cambio permanente, la formación y socialización irá dirigida a formar unos profesionales preparados no sólo con los saberes instrumentales, sino como artesanos morales, conscientes y responsables de los valores que están en juego en la situación escolar. En esta corriente la socialización se considera un aprendizaje situacional que parte de la propia práctica y que construye el saber a través de un proceso de investigaciónacción.

La corriente del "práctico-reflexivo" de Schön intenta conciliar la creatividad necesaria para tratar las situaciones siempre cambiantes de la clase, con las adquisiciones de la experiencia del pasado y las aportaciones de las ciencias pedagógicas. En esta corriente, la formación y la socialización se realiza a través del acompañamiento tutorial que desarrolla la actitud reflexiva del estudiante o profesor.

No cabe duda que en la socialización profesional del profesor influyen, además de los aspectos citados en cada uno de los modelos, las asociaciones profesionales.

La organización colegiada ha sido una de las vías empleadas por otros profesionales para proteger de la presencia de intrusos, el campo de la vida humana en el que son competentes y sobre el que ejercen un cierto monopolio en atención a la importancia del servicio que prestan.

El monopolio sobre la actividad sirve para ejercer un control en el acceso a ella (carreras largas, títulos, colegiación, códigos deontológicos, etc.) y para determinar las reglas a las que debe ajustarse su comportamiento al actuar. De esta manera pretenden garantizar un alto nivel de competencia, pero también el alza de su prestigio y de su estatus socioeconómico. La pertenencia a estos colectivos suele, además, generar un espíritu de cuerpo, que se fomenta a través de unos ritos, un lenguaje, un estilo y una simbología propios.

Este espíritu estamental que sustenta la fuerza de los colegios entra en contradicción con el principio de libre competencia de las democracias modernas y con el supuesto ideal altruista de las profesiones, máxime cuando se preocupan más de controlar el acceso de nuevos miembros que de controlar la calidad de los servicios que prestan. En la profesión docente el nivel de asociacionismo es bajo y se canaliza a través de asociaciones científicas, asociaciones de profesores y los sindicatos.

En Francia tienen una gran fuerza los sindicatos de docentes. El SGEN-CFDT (Sindicato General de los Enseñantes Franceses) y la FEN (Federación Nacional de Enseñantes). La FEN reúne los sindicatos mayoritarios de los instituteurs (el SNI-PEGC) y el sindicato de los profesores de secundaria (SNES). En 1992 el SNIPEGC se transformó en SNE, es decir, Sindicato Nacional de Enseñantes, que reúne a los profesores de primaria y secundaria. Dichos sindicatos han ejercido y ejercen una función básica en la configuración profesional de los profesores. La aspiración a la profesionalización ha conducido a los sindicatos a modificar el nombre de sus Revistas. Así el SGEN-CFDT en 1990 cambió el título de su 
boletín de "Sindicalismo universitario" por el de "Profesión: Educación". En 1992 el SNI-PEGC substituyó el título de su boletín "La escuela liberadora" por el de "Enseñantes".

En Estados Unidos existen dos grandes asociaciones: La Asociación Nacional de Educación y la Federación Americana de Profesores. Además cada grupo de profesorado específico ha desarrollado sus organizaciones locales y nacionales. Por otra parte hay otros grupos cuya finalidad es la mejora de la enseñanza como el Comité Nacional para la Acreditación de la Educación del Profesor.

En España también sabemos el importante papel que han desempeñado los sindicatos de enseñantes en la transición política, como medio de negociación de mejoras laborales, y como instrumento de información y formación. Según una encuesta de Comisiones Obreras, el grado de afiliación reconocido en primaria y secundaria está en torno al 25\%. De cada 10 docentes: 5 van a los sindicatos a informarse, 1 acude sólo cuando tiene algún problema, 2 están afiliados, y entre 1 y 2 no participan en modo alguno. Los sindicatos que consideran que mejor defienden sus intereses serían por este orden: CCOO, ANPE, FETE-UGT, STEs, CSIF, y otros (Fernández Sánchez y otros, 1993, pp. 115-137).

En otro estudio reciente (González Blasco y González-Anleo, 1993, p. 60), los datos son algo diferentes. El grado de afiliación reconocido es del $20 \%$ y se distribuyen de la siguiente forma: FETE-UGT (31\%), CCOO (18\%), STEs (8\%), CSIF (7\%), ANPE (7\%), FSIE y USO (7\%), entre otros.

\section{LOS PERÍODOS DE DESARROLLO PROFESIONAL}

Considerar a los profesores como profesionales y a la enseñanza como profesión supone aceptar su formación como un proceso de desarrollo personal y profesional que comienza con su formación inicial y que concluye cuando se jubilan.

La aceleración del cambio en todos los aspectos de la sociedad actual exige una constante puesta al día como una característica inherente a la propia tarea de enseñar. Es evidente que en el corto período de tiempo en el que transcurre la formación inicial de los docentes, es imposible darles una capacitación que incluya todos los aspectos que van a ser necesarios a lo largo de su carrera. La formación inicial, por muy bien concebida que pudiera estar, siempre resultará insuficiente, no sólo por su duración limitada, sino por el impacto que los hechos, que se suceden a ritmo vertiginoso en la sociedad, provocan en el sistema educativo: valores, procedimientos, conocimientos, métodos, formas de organización, procedimientos de investigación, recursos didácticos, etc. Frente a la actitud de quienes puedan pensar que una vez que se ingresa en una institución educativa ya se es un buen profesor para toda la vida, se hace necesario considerar la profesión docente como un proceso de formación y socialización continua, en el que a través de sucesivas etapas, se van adquiriendo y desarrollando todos los resortes personales y profesionales que van a permitir una enseñanza de calidad. El concepto de desarrollo profesional nos invita a ver a los profesores como sujetos en constante evolución y aprendizaje. 
Han sido muchos los autores que desde esta perspectiva han analizado las diferentes etapas en el desarrollo profesional del docente (Lynch, 1977; Taylor, 1980; Porter, 1980; Bolam, 1982; Freiman-Nemser, 1983; González Sanmamed, 1995 , etc.). Todas ellas se pueden resumir en tres fundamentales, cada una de las cuales tiene entidad suficiente como para ser analizadas y subdivididas por separado. Son la de la formación inicial, la de iniciación y la de formación en ejercicio. Hasta ahora, la formación inicial ha sido la que tiene una más larga tradición, es la que más atención ha recibido, y la que ha merecido mayores críticas por parte de todos los sectores: administradores, profesores, alumnos, etc. Son muchas las investigaciones que ponen en evidencia la insatisfacción de los profesores novatos, cuando se quejan de la insuficiencia de la formación recibida, para resolver los problemas prácticos con los que se encuentran en sus primeras experiencias profesionales. Una vez más hay que insistir en que la formación inicial, aun siendo fundamental, no puede estar enfocada al vano intento de dar un saber teórico-práctico acabado y definitivo, sino como el modo de adquirir los medios necesarios para sacar el máximo provecho de la experiencia y de la formación continua, es decir, como la mejor vía de facilitar e impulsar el desarrollo posterior.

\subsection{El periodo de iniciación en la profesión: fases y lineas de investigación}

Tras la formación inicial, viene la etapa de iniciación en la enseñanza, aquella en la que los profesores se enfrentan a sus primeras experiencias en la enseñanza una vez terminada la carrera, que pese a ser muy importante, quizás no ha logrado todo la atención que merece en nuestro país, hasta fechas recientes (Cebreiro, 1986, 1992; González Granda, 1987; Vera, 1988b; Marcelo, 1992). Su estudio es importante porque:

a) Permite conocer mejor el acto educativo, a través del estudio de las dificultades reales que ha de superar el profesional de la docencia en el ámbito escolar.

b) Es un momento óptimo para la evaluación de la idoneidad de los planes de formación inicial, y de su capacidad para dotar al profesor de recursos personales, sociales y científicos suficientes como para resolver los problemas habituales en su profesión.

c) Es una fuente informativa muy potente para extraer conclusiones valiosas que ayuden a diseñar, a partir de las necesidades reales detectadas, los programas de formación para el profesorado en ejercicio.

d) Es un momento clave para impulsar las medidas preventivas de posibles enfermedades laborales y, especialmente, del fenómeno del malestar docente, de modo que no se acumulen dosis de estrés, y posteriormente, ansiedad que, a la larga, amenazan con poner en peligro la salud del profesor.

e) El conocimiento de las dificultades reales de los profesores en fases tempranas de su socialización profesional, es el primer paso para articular políticas de formación centradas en la escuela, como marco en el que surgen las dificultades, y ámbito desde el que han de ser resueltas muchas de ellas. 
El profesor principiante ha de realizar una triple transición: a) de la universidad al centro escolar, b) de alumno a profesor, y c) de la teoría a la práctica. Ese tránsito se caracteriza por la confrontación entre la imagen de la profesión elaborada mientras se está desempeñando el rol de alumno en los centros de formación del profesor, y la adaptación a las situaciones reales en las aulas. A lo largo de este período, el profesor principiante debe resolver autónomamente un abanico de situaciones diferentes haciendo uso de los recursos profesionales adquiridos en el período de formación, a la vez que va conociendo la realidad escolar en sus diferentes niveles: el docente, el relacional, el organizativo, etc., de modo que cada una de esas experiencias representa una autoconfrontación con su propia capacitación que contribuye a moldear la imagen de la profesión que acabará orientando las actitudes, hábitos y expectativas del profesor en el futuro.

Este momento que Vonk $(1983,1985)$ califica de socialización profesional, recibe en la literatura inglesa y alemana sobre el tema, las denominaciones de "shock de la realidad", "shock de la transición" y "shock de la praxis". En general, el concepto se usa para indicar la confrontación entre el estereotipo idealizado adquirido en el período de estudios y la cruda y ruda realidad de la vida cotidiana en el aula (Cfr. Veenman, 1984, p. 143; Nickel, 1981, p. 114). Es un período de asimilación de una realidad compleja que se impone incesantemente, día tras día, al profesor debutante y que puede tener unas consecuencias trascendentales para la conformación de su rol docente y la adaptación a su entorno profesional.

Este proceso que siguen los profesores para aprender no es uniforme ni idéntico en todas sus fases, sino que por el contrario, en su transcurso se producen experiencias y aprendizajes que completan y complementan el bagaje pedagógico anteriormente adquirido, afectando la personalidad del debutante y la manera en que éste percibe y asume su nuevo rol de profesor (Huberman, 1989). Algunos estudios se han orientado a descubrir las características de estas etapas, desde un punto de vista evolutivo (Fuller, 1969, 1975; Vonk, 1983, 1985; Buitink y Kemme, 1986).

Los estudios que siguen el enfoque evolutivo tienen sus orígenes en los primeros trabajos de Fuller (1969). Para este autor se suceden tres momentos correlativos en el proceso inicial de socialización profesional, en cada uno de los cuales se aprecian núcleos de preocupaciones característicos. Estos momentos son: a) la etapa en la que el sujeto se prepara para ser profesor; b) el período de iniciación o debut en la enseñanza; y c) el período de madurez o consolidación.

Respecto a los futuros enseñantes que se hallan en período de prácticas y que, por lo tanto, no han tenido oportunidad de asumir totalmente la responsabilidad de la enseñanza de un grupo de alumnos, Coates y Thorensen (1976, pp. 162-164) llegaron a la conclusión de que tienen unas preocupaciones marcadamente centradas en las dudas y vacilaciones respecto a su grado de competencia profesional; respecto a la aceptación y reconocimiento que su labor va a merecer en la comunidad escolar y respecto a la capacidad para relacionarse con el grupo de sus alumnos y el dominio de las materias.

En cambio a lo largo del primer año de experiencia docente, se suceden, fundamentalmente dos períodos diferentes que marcan la forma en que el debutante afronta sus vivencias profesionales (Vonk, 1983, 1985): 
a) El periodo de umbral o antesala abarca globalmente los cinco o seis primeros meses. Se caracteriza por producirse en él la primera confrontación con el colegio y con la clase.

Para la mayoría de los maestros es la primera vez en su vida que se sienten responsables de un grupo de alumnos. Es un período de inseguridad, en el que se duda de que el modo de afrontar los problemas sea el más adecuado. Se tiene temor a que los errores propios conduzcan a consecuencias irreparables y predomina un sentimiento de soledad. La vivencia de las primeras experiencias escolares y su disonancia respecto a las expectativas generadas en el período de formación hacen que se inicie un cambio en su concepción del rol profesional. El debutante comienza a darse cuenta de que los alumnos están habituados a responder ante medidas disciplinarias, de que se sienten inseguros ante situaciones muy abiertas en las que sus conductas no han sido estipuladas previamente por el maestro, de que sólo trabajan bajo presión, etc. Hay por lo tanto una inadaptación al clima social de la escuela y de la clase debido a la divergencia en las expectativas de los elementos personales de la institución.

Los datos recogidos en la investigación durante el período de umbral dieron como resultado un conjunto de dificultades que una vez agrupadas y categorizadas quedaron de la siguiente forma:

- problemas con el contenido del material de aprendizaje,

- problemas con la organización de las actividades de enseñanza/aprendizaje,

- problemas relativos a la disciplina, al establecimiento de normas de comportamiento y control de los alumnos,

- problemas debidos a la falta de motivación y participación de los alumnos,

- problemas relacionados con los sentimientos de los maestros respecto a su desarrollo personal,

- problemas en las relaciones con determinados alumnos,

- problemas relacionados con la organización de la escuela,

- problemas relacionados con los compañeros,

- problemas relacionados con la dirección de la escuela, y por último,

- problemas en las relaciones con los padres de los alumnos.

b) El periodo de maduración o crecimiento comprende los meses siguientes. Se caracteriza por la aparición en el maestro novel de un sentimiento de aceptación por parte de los niños y de sus compañeros. Comienza a ensayar comportamientos más acordes con la situación dada que se prolongarán en el segundo año y ahora se siente con niveles de seguridad que le impulsan a ensayar estrategias menos rígidas y a poner en práctica aprendizajes adquiridos durante su período de estudios. 1985):

El período de crecimiento puede ser caracterizado como sigue (Vonk, 1983,

- El profesor se acepta a sí mismo en su rol profesional que comienza a ajustarse a las características personales.

- El profesor se siente más aceptado en su papel profesional por toda la comunidad escolar.

- Se produce una disminución de los problemas con las materias. 
- El profesor se siente suficientemente seguro como para experimentar otras formas de enseñar y otras maneras de organizar la enseñanza y las actividades de aprendizaje.

- Tiene lugar una disminución en el empleo de medidas de castigo.

- Hay una aceptación mayor de las peculiares características de cada grupo de alumnos.

- El novel se siente más integrado en la estructura organizativa del centro e interviene con más convicción en la toma de decisiones.

Fuller cree que las preocupaciones posteriores no pueden emerger y ser afrontadas hasta que las más tempranas han sido resueltas, por lo que la experiencia de desarrollo profesional significa tener que vérselas con cada uno de los estadios. Un conocimiento más profundo de todo este proceso permitiría abordar cada una de las etapas durante la formación inicial y el período de prácticas, para de esta forma aumentar los sentimientos de autoestima y la seguridad en sí mismos de los debutantes.

Un segundo enfoque se basa en teorías que explican la evolución humana como resultante de cambios acontecidos en la estructura cognitiva. Las personas con más nivel de desarrollo funcionan de forma más compleja, poseen un repertorio más amplio de habilidades, perciben los problemas con más amplitud y pueden responder con más precisión y empatía a las necesidades de los demás. Entre los docentes, se aprecia que aquellos que poseen un mayor desarrollo cognitivo, funcionan mejor en el aula, son más flexibles, toleran mejor el estrés, son más adaptativos, y tienen más habilidad para afrontar los problemas (Glassberg, 1980; Hunt y Joyce, 1981; Sprinthall y Thies-Sprinthall, 1983). Un mejor conocimiento de las diferencias en los niveles de desarrollo cognitivo de los debutantes puede ayudarnos mejor a comprender la estructura y el contenido de sus problemas y a diseñar programas educativos para afrontarlos.

Otro enfoque desde el que se ha estudiado el período de iniciación en la enseñanza es el sociológico, que contempla al profesor principiante desde la perspectiva de la socialización profesional mediante la cual aprende e interioriza las normas, valores, conductas, actitudes, etc. que caracterizan a la cultura escolar en la que se integran.

Lacey (1977) ha identificado tres estrategias sociales bien diferenciadas que los profesores utilizan para integrarse en la microcultura establecida por la comunidad escolar:

a) Ajuste interiorizado, mediante el cual el profesor asume como propias las normas, valores y objetivos de la institución, con lo que inconscientemente reduce la posibilidad de conflicto.

b) Aceptación estratégica, que implica manifestar un apoyo público a las normas establecidas, aun cuando se mantienen ciertas reservas personales en privado.

c) Redefinición estratégica, mediante la cual se asumen los propios puntos de vista y se cuestionan con independencia de juicio los aspectos institucionales con los que no hay coincidencia. En esta fase el sujeto ha alcanzado un nivel de madurez que le permite aprovechar al máximo sus cualidades personales, sin miedo a la discrepancia con otros miembros de la institución. 
A este respecto, algunos estudios centrados en el análisis de los cambios de actitudes que experimentan los debutantes sugieren que el impacto de los cursos de formación se desvanece con la experiencia diaria en la escuela, debido a las fuertes presiones ejercidas por el clima escolar sobre el comportamiento y la toma de decisiones de los jóvenes docentes. Entre estos factores del clima escolar que incidirían más notablemente estarían las normas burocráticas de los centros; los profesores supervisores de prácticas, los directores, los inspectores y otros elementos personales de la organización escolar con poder evaluador sobre los maestros en prácticas, y debutantes; las características de la estructura organizativa de la escuela y el modo de funcionamiento de los maestros; el ambiente ecológico de la escuela, es decir, lo que podríamos denominar como el clima social escolar; el grupo de colegas como marco de referencia de lo socialmente aceptado como correcto; los alumnos y padres; y la propia biografía de los futuros enseñantes (Doyle, 1977; Copeland, 1980; Petty y Hogben, 1980). De esta manera podríamos hablar de una socialización acorde con un modelo idealizado en la Escuela de Magisterio y una segunda socialización adaptativa a la realidad escolar lejos ya de la esfera de influencia del centro en el que los profesores se formaron. La teoría de la disonancia cognitiva ofrece un excelente marco teórico desde el cual examinar conceptualmente el cambio de actitudes. Esta teoría mantiene que si las personas sufren una disonancia cognitiva durante demasiado tiempo, probablemente cambiarán sus actitudes para disminuir la disonancia y sus efectos tensionantes.

Por último, muchos trabajos han coincidido en resaltar la mayor vulnerabilidad de los profesores novatos ante el malestar docente (Kyriacou y Sutcliffe, 1978; Mandra, 1984; Breuse, 1984a y 1984b; Amiel y otros, 1986; Esteve, 1987), lo cual no es sino una razón más que justifica el esfuerzo por conocer mejor la caracterización de este período en la vida del docente, de modo que sea posible diseñar estrategias de intervención que le doten de las técnicas para solventar, sin grandes traumas, las dificultades cotidianas de la enseñanza en el momento presente.

Según Amiel (1986) las motivaciones por las que se elige la profesión y la imagen idealizada que se tiene de ella al comienzo, están en el origen de muchos de los conflictos posteriores. En los inicios de la carrera docente, muchas veces se descubre que la enseñanza es una realidad sustancialmente diferente. A falta de aquella imagen primera elaborada durante la formación inicial, el profesor principiante se encuentra con imágenes divergentes surgidas de las expectativas contradictorias de los padres, los alumnos, los directores, los compañeros, etc., de suerte que está en permanente peligro de cuestionarse a sí mismo.

Como señala Esteve (1984), los profesores que intentan imitar los estereotipos aprendidos durante su formación olvidándose de sus propias cualidades personales, corren el riesgo de pasar de la idealización inicial a la decepción, debido a la angustia que produce la constante comparación de las características propias con las cualidades del estereotipo ideal. "La adopción de posturas fingidas, intentando responder a estos estereotipos se constituye, a medio plazo, cuando el profesor ya no puede seguir fingiendo, en una fuente de ansiedad que llega a plantear serios problemas de identidad" (pp. 229-230). 
Müller-Fohrbrodt y cols. (1978) señalan como manifestaciones específicas del shock del principiante: la aparición de problemas experimentados subjetivamente como tensionantes; los cambios de conducta debidos a presiones externas; la aparición de alteraciones en el propio sistema de creencias, como por ejemplo, el paso de actitudes tolerantes o permisivas al acabar el período de formación, a posiciones más directivas o autoritarias en las primeras relaciones con los alumnos; cambios en el dominio emocional (estabilidad/inestabilidad) y en el concepto de sí mismo; y finalmente, cuando el choque con la realidad es excesivamente fuerte, la desilusión y el desánimo, pueden conducir al novato al abandono de la profesión o, si ello no es posible, a la adopción de mecanismos de evasión más sutiles y discretos como pueden ser el absentismo, el refugio en una actuación rutinaria en la que predomina la inhibición, el cambio de curso, el traslado a otro centro, etc.

\subsection{Consecuencias para la formación inicial de los profesores}

Los estudios sobre el profesor principiante y sus dificultades, han de servir para optimizar los programas de su formación inicial. En estos trabajos (Vera, 1988b) los principiantes se quejan de una escasa formación en técnicas relacionales, en cambio de actitudes, en dinámica de grupos y en el análisis sociológico y psicológico de las motivaciones subyacentes al funcionamiento de los grupos. Muchos debutantes se sienten faltos de recursos dialécticos y de una buena base teórica, en aquellas situaciones en las que, discrepando del criterio de los padres, deben justificar las razones de sus decisiones profesionales. Del mismo modo, echan de menos un bagaje de recursos metodológicos, de programación y de evaluación, lo suficientemente amplio y flexible como para saber adecuar la actuación profesional a la diversidad de situaciones a las que han de hacer frente.

Los planes de formación deberían tener en cuenta el efecto paralizante provocado por el choque con la realidad, que disminuye la capacidad de los profesores para adecuar los conocimientos adquiridos a su situación escolar. Por ello, parecen aconsejables las prácticas de inmersión durante el período de prácticas; y, de otra parte, las prácticas de simulación con técnicas tales como las de inoculación de estrés (Esteve, 1986), que permitan reafirmar la seguridad del profesor en sí mismo y potenciar su habilidad para hacer frente a las situaciones profesionales más frecuentes. También pueden ser muy útiles técnicas de aprendizaje de destrezas sociales en situaciones simuladas, a través de las cuales, cada profesor tenga oportunidad de encontrar la manera personal de responder ante tópicos previamente identificados en la investigación, de aclarar sus propósitos, de justificar su toma de decisiones, etc.

Estas y otras medidas pueden elevar la capacidad de los enseñantes para resolver los problemas técnicos de su profesión, pero debe quedar claro que la optimización de la formación debe ir acompañada de otro tipo de medidas que la incentiven y le den consistencia. Por citar sólo algunas que parecen necesarias, señalaremos la de dotar a los centros de mayor autonomía, la de estabilizar al profesorado en su puesto de trabajo durante el tiempo necesario para que desarrolle 
los proyectos educativos en marcha, la asignación de plazas en correspondencia con la especialidad cursada, y la apertura de vías de promoción dentro de la propia profesión. Estas sugerencias se pueden resumir en tres ideas directrices: incentivar el autoperfeccionamiento, posibilitar la puesta en práctica de lo aprendido y recompensar el esfuerzo superador.

La formación inicial y la formación en ejercicio son importantes, pero no debemos olvidar que, en los primeros años de práctica profesional, se forjan y consolidan la mayor parte de los hábitos y actitudes que guiarán en el futuro la acción del profesor, por eso merece la pena prestar atención a este período.

\subsection{Consecuencias para el establecimiento de dispositivos formativos en el período de iniciación profesional}

Las necesidades profesionales asociadas a los primeros años de ejercicio en la docencia son la base para el diseño de los Programas de inducción o iniciación para profesores noveles (Beginning Teacher Induction), puestos en práctica en Inglaterra (Evans, 1978) y otros países, para aminorar las dificultades asociadas a los comienzos profesionales en la enseñanza.

Wilson y D'Arcy (1987, p. 143) definen la iniciación como "el proceso mediante el cual la escuela lleva a cabo un programa sistemático de apoyo a profesores de cara a introducirles en la profesión, ayudarles a abordar los problemas de forma que refuerce su autonomía y facilite su continuo desarrollo profesional".

Los planes de inducción son estrategias de ayuda organizadas para facilitar la asimilación del rol de profesor en los primeros años de ejercicio profesional. Estas estrategias se centran en ayudar a los profesores a analizar sus propias vivencias profesionales, a asimilar la realidad de los centros y estimular la reflexión sobre la práctica. La experiencia demuestra que de esta manera afrontan mejor las tensiones de su trabajo, ofrecen más resistencia a abandonarse acríticamente a la rutina del centro, se potencian las respuestas constructivas ante las influencias socializadoras del medio y se facilita la contrastación entre la teoría y la práctica (Nickel, 1981; Vonk 1983, 1984).

Los programas de ayuda suelen diseñarse teniendo en cuenta las necesidades reales de los profesores noveles de una determinada zona o un tipo concreto de centros que presenten una cierta homogeneidad. Es importante que ellos mismos participen en el diseño de las fases y las actividades que van a realizar, siendo corriente el uso de instrumentos como diarios de clase o autobiografías, cuestionarios, entrevistas individuales, estudio de casos, grupos de discusión, servicios de asesoramiento y ayuda permanente, la reducción de la carga docente durante el primer año entre un 10 y un 20\%, y otros (Darder, Izquierdo y Vilaplana, 1991; Marcelo, 1992).

Para llevar a cabo estos planes, es muy útil la figura del tutor-formador o mentor que puede ser un profesor del centro con experiencia y especialmente capacitado para ponerse en el lugar del otro y transmitir la empatía necesaria para que sea factible la comunicación cooperativa. Puede hacerse también en coordinación con centros de formación del profesorado, como Facultades, Ceps, o Institutos de 
Ciencias de la Educación, lo cual permite abrir un campo interesante para la innovación e investigación educativas en este terreno.

\section{SALUd laboral y ENFERMEDADES PROFESIONALES DE LOS PROFESORES}

Entendemos por salud el estado de completo bienestar físico, mental y social en el que el individuo es capaz de desarrollar todas sus potencialidades creativas. Estar sano no es lo mismo que no estar enfermo. En lo que respecta a la salud laboral se pueden identificar tres tipos de daños: a) accidentes, b) enfermedades profesionales y c) enfermedades comunes desencadenadas o agravadas por el trabajo.

Se entiende que son enfermedades profesionales aquellas cuya causa es directamente identificable con un factor del ambiente de trabajo y que son reconocidas como tales por la legislación laboral. Por ejemplo, la sordera profesional causada por el ruido. Una de las características principales de la enfermedad profesional es que aparece lentamente, sin que el trabajador note en un principio que va perdiendo salud. De ahí la importancia de los dispositivos médicos preventivos.

Además de las laborales, existen enfermedades comunes desencadenadas o agravadas por el trabajo. Son una serie de padecimientos físicos o psíquicos que pueden producirse también fuera del trabajo o en personas que no trabajan, pero en las cuales, el ambiente laboral puede actuar como predisponiente, desencadenante o agravante, por ejemplo, las enfermedades psíquicas, digestivas, etc. Al no existir la referida relación de causa-efecto entre la labor desarrollada y la enfermedad sufrida, no son consideradas como enfermedades laborales.

Existe la idea muy extendida de que los daños a los que está expuesto un profesional de la enseñanza son mínimos y, siempre relacionados con riesgos físicos. Sin embargo, los datos de los que, poco a poco, vamos disponiendo sobre bajas laborales revelan la importancia creciente de los riesgos psicológicos. En el Cuadro de Enfermedades Profesionales actualmente en vigor, regulado por el Real Decreto 1995/78, de 12 de mayo, y sus posteriores modificaciones no existen enfermedades profesionales, calificadas propiamente como tales, en el ámbito docente (Consejo Escolar del Estado, 1996).

Una de las mayores dificultades para el estudio de las enfermedades laborales de los docentes ha sido, hasta ahora, la ausencia de datos fiables para todo el territorio español, así como para cada una de las Comunidades Autónomas, lo que limita mucho la capacidad negociadora de los sindicatos sobre medidas de salud laboral. Del estudio descriptivo de bajas por enfermedad del personal docente no universitario, en el ámbito gestionado directamente por el MEC, se desprenden las siguientes conclusiones importantes (Cfr. Consejo Escolar del Estado, 1996):

a) El porcentaje de docentes con baja por enfermedad respecto del censo total del profesorado, ha pasado del 17,66\% en el curso 93/94 al 19,68\% en 94/95, es decir, aumentó en dos puntos, a pesar de haber disminuido ligeramente la afectación por embarazos.

b) La mayor proporción de bajas corresponde a los profesores de primaria con un $23,30 \%$, frente al $20,17 \%$ de los de secundaria, habiéndose producido un incremento en los dos sectores. 
c) Las mujeres, con un 20,17\% están más afectadas que los hombres con un $14,30 \%$, aun teniendo en cuenta la desviación que ocasionan las bajas por maternidad, las ginecológicas y las obstétricas.

d) Con relación a la edad, las bajas, al igual que en años anteriores, afectan más a los profesores jóvenes. Como razones se alude la política de jubilaciones llevada a cabo por el Ministerio y la juventud de los profesores de secundaria.

e) Por especialidades médicas, las que registraron más bajas fueron: traumatología (3.811), enfermedades infecciosas (3.590), reumatología (3.379) y otorrinolaringología (3.356). En el informe se destaca el aumento de depresiones y el alto riesgo de los docentes ante la gripe.

f) En cuanto a la proporción de los días de baja por enfermedad, el primer lugar lo ocupan las enfermedades traumatológicas con 184.021 días y un $13,40 \%$, seguidas de las neuropsiquiátricas con 181.000 días y un $13,18 \%$, de las reumatológicas con 167.810 días y un $12,22 \%$ y, a más distancia, las ginecológicas con un $5,50 \%$ y 76.868 días. Por contra, las enfermedades infecciosas suponen sólo un 2,65\% del total de días de baja.

g) El número total de días de ausencia por enfermedad ha aumentado, con respecto a años anteriores, situándose en 1.373.539, mientras que la duración media de todos los procesos ha bajado y se sitúa en 40,56 días. El coste económico de estas bajas supera los 14.000 millones de pesetas, lo que da una idea de lo barato que puede resultar estudiar y poner en marcha un plan de prevención en materia de salud laboral. Este cálculo es una extrapolación de los empleados por Miguel Recio para el curso 94-95 (1994, p. 26).

La importancia que dentro de este colectivo tienen las bajas en otorrinolaringología y en psiquiatría, en relación con otros colectivos profesionales, y el hecho de que este fenómeno sea recurrente en muchos otros países, da pie para pensar que estamos ante un cuadro típico de la profesión docente, aunque, probablemente, no exclusivo de ella. Además, en ambos grupos de enfermedades se ha producido un incremento muy notable de profesores afectados. Este tipo de enfermedades como las disfonías, en el caso de los profesionales de la enseñanza, deben ser consideradas de carácter profesional, pues su actividad conlleva características que las originan o las fomentan.

En concreto, sobre las bajas psiquiátricas se debe tener en cuenta varios datos que pueden servir para calibrar su importancia relativa dentro del colectivo, y no pecar ni de exageración, ni de despreocupación. Nos vamos a basar, sobre todo en los datos de Esteve, Franco y Vera (1995) y de García Calleja (1991):

a) Desde el curso 82/83 al 88/89 el número de profesores no universitarios en baja psiquiátrica creció en la provincia de Málaga un 110\%, mientras que el número de profesores lo hizo en un $28,2 \%$. No obstante, el porcentaje de profesores en baja psiquiátrica respecto del total de profesores (en baja o no) pasó del $0,77 \%$ al $1,26 \%$ del total. Si admitimos los casos de enfermedad encubierta y no declarada podemos estar hablando tal vez de un 2 ó 3\% del profesorado que podría causar baja por desgaste psíquico. 
b) La psiquiatría suele aparecer, en los estudios más recientes, entre el tercer y quinto puesto entre las especialidades médicas por el número de profesores que causan baja.

c) Afectan en torno al $8 \%$ del total de profesores no universitarios en baja y, en torno al 1,3\% del total de profesores.

d) La depresión es uno de los diagnósticos más frecuentes del total de los procesos diagnosticados a los profesores de baja (en $2^{\circ}$ lugar en el estudio de García Calleja y en $3^{\circ}$ en el de Esteve, Franco y Vera).

e) La bajas psiquiátricas están entre las que más días de baja provocan. Afectan más a las mujeres que a los hombres y a los profesores de primaria más que a los de secundaria, aunque ambos factores se refuerzan puesto que hay más mujeres en el primer nivel que en el segundo.

Otro aspecto interesante que llama la atención, es el estudio del denominado ciclo de estrés en la enseñanza, desarrollado a partir del trabajo de Hembling y Gilliland (1981) y analizado en España por Esteve (1987, 1995). Según esta hipótesis es posible identificar unos ciclos de estrés en la enseñanza que se distribuyen a lo largo del curso escolar, con sus tres picos más altos en los comienzos de los trimestres (aumento de las bajas por enfermedad), hasta que un período de vacaciones viene a romper la tensión acumulada (disminución de las bajas por enfermedad). En esta misma línea apunta el último informe del Consejo Escolar del Estado cuando afirma que "el número total de bajas va aumentando a medida que transcurre el primer trimestre, produciéndose una caída en diciembre [...]. A partir del comienzo del segundo trimestre el número de bajas sube ininterrumpidamente hasta conseguir el máximo anual en el mes de marzo. Desde el comienzo del tercer trimestre las bajas totales comienzan a descender [...]" (1996, p. 441).

Los estudios realizados hasta ahora acerca de la salud de los profesores, ponen en evidencia la necesidad de adoptar medidas para frenar el progresivo deterioro de su salud y prevenir sus consecuencias. En este sentido, parece necesario abordar algunos aspectos de los que se vienen ocupando los sindicatos de la enseñanza:

a) Elaboración de un cuadro de enfermedades profesionales del sector educativo.

b) Elaboración de un plan de prevención que identifique los factores de riesgo en el ambiente laboral de la enseñanza.

c) Determinar las condiciones de seguridad y riesgo que tienen en la actualidad los centros de trabajo.

d) Desarrollar estructuras de ayudas para los trabajadores afectados por bajas de larga duración. En el momento actual, las bajas sólo suponen un período de recuperación con tratamiento médico, tras el cual los profesores vuelven a reintegrarse a su trabajo en las mismas condiciones que provocaron su baja, con lo cual el riesgo de recaída, sobre todo en trastornos psiquiátricos, es grande. Se hace necesario instaurar procesos de rehabilitación posteriores a las bajas que ayuden a los profesores a reincorporarse paulatinamente a su lugar de trabajo, incluso a través de su reclasificación en puestos no docentes, si fuera necesario. En este sen- 
tido, pueden ser un buen referente los dispositivos con los que cuenta la Mutualidad de Funcionarios en Francia.

e) Por último, como ya ha hemos mencionado, conviene establecer programas preventivos en el período de formación inicial de los profesores que incluyan una información acerca de la profesión, alejada de las idealizaciones a las que estamos tan acostumbrados, y técnicas de prevención del estrés, la ansiedad, las disfonías, los dolores musculares, y demás afecciones relacionadas directa o indirectamente, con el ejercicio de la profesión. Si tenemos en cuenta el enorme gasto que suponen las bajas laborales, se comprenderá que una política preventiva puede ser rentable, no sólo desde el punto de vista de la satisfacción laboral y de la calidad de la enseñanza, sino también desde parámetros estrictamente económicos.

\section{BiBLIOGRAFÍA}

ABDAL-HaGg, I. (1995): Professional Standars Development: Teacher Involvement. Office of Educational Research and Improvement (ED). Washington, D.C.

ABraHAM, A. (1986): El enseñante es también una persona. Gedisa. Barcelona.

- (1987): El mundo interior de los enseñantes. Loria. Barcelona.

ADAMS, (1982): "A look at changes in teacher perceptions and behavior across time". Journal of Teacher Education, 33, 4, pp. 40-43.

Albuerne, F., García, G. y Rodríguez, M. (1986): Las Escuelas Universitarias de Magisterio: Análisis y alternativa. ICE de la Universidad de Oviedo. Oviedo.

Amiel, R. y OTROS. (1986): "La salud mental de los enseñantes". En ABRAHAM, A. Y COLS.: El mundo interior del docente. Gedisa. Barcelona.

APPLE, M. (1989): Maestros y textos: una economia politica de las relaciones de clase y género en educación. Paidós. Barcelona.

AskLING, B. y ALmEN, E. (1995): Governing Schools and Developing Professionalism: Complementary or Contradictory Tasks in Teacher Education. Linkopings Universitet. Lararutbildningen. Sweden.

Ball, S. I. (comp.) (1990): Foucault y la educación. Disciplinas y saber. Ediciones Morata. Madrid.

BÁRCENA, F. y JOVER, G. (1991): "El carácter ético de la actividad educativa. Notas críticas para el replanteamiento de un problema". Bordón, no 3, pp. 259-269.

BENEJAM, P. (1986): La formación de maestros. Laia. Barcelona.

Bolam, R. (1982): La formation en cours de service des enseignants: condition du changement a l'école. OCDE. Paris.

Borja, M. Y OTROS (1990): Coeducació o sexisme a la universitat. La Llar del llibre. Barcelona.

BOURDONCLE, R. (1994): "La professionnalisation des enseignants". European Journal of Teacher Education, vol. $17, \mathrm{n}^{\circ} \mathrm{1} / 2$, pp. 25-29.

BREMBECK, C. S. (1976): El maestro y la escuela. Roles sociales y profesionales. Paidós. Buenos Aires.

BREUSE, E. (1984a): “Identificación de las fuentes de tensión en el trabajo profesional del enseñante». En Esteve, J. M.: Profesores en conflicto. Narcea. Madrid, pp. 143-161.

- (1984b): "L'enseignant debutant". Recherche en Education, 29. Direction Generale de L'organisation des Études. Bruxelles. 
BurTINK, J. Y Kemme, S. (1986): "Changes in student-teacher thinking". European Journal of Teacher Education, 9, 1, pp. 75-84.

Burbules, N. C. y Densmore, K. (1992a): "Los límites de la profesionalización de la docencia”. Educación y Sociedad, no 11, pp. 67-83.

- (1992b): "La persistencia del profesionalismo: Es duro abrirse camino". Educación y Sociedad, no 11 , pp. 97-104.

CARDOna, C. (1990): Etica del quehacer educativo. Rialp. Madrid.

CARR, W. Y Kemmis, S. (1988): Teoría de la enseñanza. Martínez Roca. Barcelona.

CARr. W. (1993): Calidad de la Enseñanza e Investigación-Acción. Díada Editora. Sevilla.

CASE, C. W., LANIER, J. E. ET AL. (1986): "The Holmes group report: Impetus for gaining professional status for teachers". Journal of teacher Education, 37 (4), pp. 36-43.

Cebreiro, B. (1986): Los primeros años de la docencia: un estudio exploratorio. Tesis de Licenciatura. Universidad de Santiago.

- (1992): La iniciación: análisis de las interacciones entre el profesor novel y las instituciones. Tesis doctoral. Universidad de Santiago.

COATES, T. J. Y THORENSEN, C. E. (1976): “Teacher anxiety: A review with recommendations". Review of Educational Research, 46, 2, pp. 159-184.

Colom, A. J. (1986): "Pensamiento tecnológico y teoría de la educación". En Castillejo, J. L. Y OTROS: Tecnologia y educación. Ceac. Barcelona, pp. 13-30.

CONSEJO ESCOLAR DE EUSKADI (1995): "La profesionalidad docente hoy", VI Jomades de Consells Escolars de Comunitats Autónomes $i$ de l'Estat. Generalitat de Catalunya. Barcelona, pp. 139-169.

CONSEJO ESCOLAR DEL ESTADO (1996): Informe sobre el estado y situación del sistema educativo. Curso 1994-95. Ministerio de Educación y Cultura. Madrid.

Consejo General de Colegios Oficiales de Doctores y licenciados en Filosofía y Letras y en Ciencias (1994): “Borrador del Código Deontológico". Boletín del Colegio de Doctores y Licenciados, febrero, pp. 19-20.

CONSEll Escolar DE CATALUNYa (1993): "Criterios para una deontología docente». Boletín del Colegio de Doctores y Licenciados, abril, pp. 5-18.

- (1995): "La profesionalidad en el ámbito de la educación". VIJornades de Consells Escolars de Comunitats Autónomes $i$ de l'Estat. Generalitat de Catalunya. Barcelona, pp. 79-96.

CONTRERAS Domingo, J. (1987): "De estudiante a profesor. Socialización y aprendizaje en las prácticas de enseñanza”. Revista de Educación, no 282, pp. 203-231.

COPELAND, W. (1980): "Student teachers and cooperating teacher: An ecological relationship". Theory into Practice, 18, pp. 194-199.

Covalewskie, J. F. Y Howley, A. (1994): «Education and the Commons: Issues of Professionalization". Educational-Fundations, vol. 8, n 4, pp. 59-73.

Cuadernos de Pedagogía Revista. Monográfico “El Profesorado”. № 220-Dic. 1993.

DARDER, P., IZQUIERDO, C. Y VILAPLANA, E. (1991): La formación permanente del profesor novel: El grupo de inducción cooperativo. Informe sumario de un plan de investigación-formación. Institut de Ciències de L'Educació. Universitat Autònoma de Barcelona.

DARLING, H. (1996): "The Quiet Revolution: Reathinking Teacher Development". Educational Leadershi, vol. 53, no 6, pp. 4-10.

DEPARTAMENT D'ENSENYAMENT (1994): L'opinió pública i l'ensenyament a Catalunya. Generalitat de Catalunya. Barcelona.

DoYle, W. (1977): “Learning the classroom environment: an ecological analisis". Journal of Teacher Education, 28, 6, pp. 51-55.

ELLIOT, P. (1975): Sociologia de las profesiones. Tecnos. Madrid.

(C) Ediciones Universidad de Salamanca

Teor. educ. 10,1998 , pp. 95-144 
ELLIOTT, J. (1991) "Actuación profesional y formación del profesorado". Cuadernos de Pedagogia, no 191, pp. 76-80.

Esteve, J. M. (ed.) (1984): Profesores en conflicto. Narcea. Madrid.

Esteve, J. M. (1986): «Inoculation against stress: a technique for beginning teachers". European Journal of Teacher Education, 9, 3, pp. 261-269.

- (1987): El malestar docente. Laia. Barcelona.

- (1989a): «Strategies cognitives pour eviter le malaise des enseignants: l'induction du stress et la désensibilisation systématique.. Education, 213 y 214 , pp. 9-18 y pp. 9-15.

- (1989a): "Teacher burnout and teacher stress". En COLE Y WALKER (eds): Teaching and Stress. Open University Press. Milton Keynes, pp. 4-25.

- (1989b): "Training teachers to tackle stress". En COLE Y WALKer (eds): Teaching and Stress. Open University Press. Milton Keynes, pp. 147-159.

- (1994): "El profesor ante la enseñanza como actividad profesional. Nuevos objetivos para una nueva etapa de la educación". En VV.AA.: Què vol dir ser professional de l'ensenyament? Cruilla. Barcelona, pp. 75-131.

- Franco, S. y Vera, J. (1991): "La salud de los profesores. Evolución de 1982 a 1989". Cuadernos de Pedagogia, no 192, pp. 61-67.

- (1995): Los profesores ante el cambio social. Anthropos. Barcelona.

- (1996): "El profesor ante el cambio social" Seminario sobre Reformas educativas y formación del profesorado. Universidad de Murcia (Texto policopiado).

Etzioni, A. (De) (1966): The Semi-professions and their Organization. Free Press. Nueva York.

Evans, N. (1978): Beginning teaching in professional partnerships. Hodder and Stoughton. London.

FERnández, F. (1996): "El docente, intelectual crítico". Cuadernos de Pedagogía, n² 251, pp. 74-79. Barcelona.

FERnÁNDEZ Enguita, M. (1990): La escuela a examen. Eudema. Madrid.

- (1993): La profesión docente y la comunidad escolar: crónica de un desencanto. Morata. Madrid.

FERNÁNDEZ PÉREZ, M. (1988): La profesionalización docente. Escuela Española. Madrid.

FERNÁNDEZ SÁNCHEZ, Mª . M. Y OTROS (1993): Encuesta al profesorado de primaria y secundaria de la enseñanza pública. Federación de enseñanza de CC.OO./CIDE. Madrid.

FRANCO MARTÍNEZ, S. (1994): Estrés laboral docente: estudio comparativo con la profesión de enfermería. Tesis doctoral. Universidad de Málaga.

FREIDSON, E. (1978): La profesión médica. Península. Barcelona.

Freiman-Nemser, S. (1983): Learning to teach. Occasional Paper, 64. Institute for Research on Teaching. Michigan State University. East Lansing. Michigan.

FulleR, F. F. (1969): "Concerns of teachers: a developmental conceptualization". American Educational Research Journal, 6, pp. 207-266.

García Calleja, M. (1991): “Enfermedades del profesorado: Análisis y prevención”. Cuadernos de Pedagogia, no 192 , pp. 67-72.

García CARRAsco, J. (1980): “Ciencia de la Educación y profesiones pedagógicas - Problemas académicos y curriculares". La investigación Pedagógica y la Formación de Profesores. VII Congreso Nacional de Pedagogía. Sociedad Española de Pedagogía. Madrid, pp. 359-376.

- (1983): La Ciencia de la educación. Pedagogos ¿para qué? Santillana. Madrid.

- (1988): "Estatuto del profesorado y carrera docente". Actas del IX Congreso Nacional de Pedagogía. Alicante, pp. 621-640. 
- (1988): “La profesionalización de los profesores". Revista de Educación, nº 285, pp. 111-123.

- (1996): "El paradigma de la complejidad en la formación del profesorado". Seminario sobre Reformas educativas y formación del profesorado. Universidad de Murcia (Texto policopiado).

Gervilla, E. (1991): "Deontología educativa". Revista de Ciencias de la Educación, no 148, pp. 441-453.

GHILARDI, F. (1993): Crisis y perspectivas de la profesión docente. Gedisa. Barcelona.

GIL, F. (1996): Sociología del profesorado. Ariel. Barcelona.

GIMENO, J. (1993): "Conciencia y acción sobre la práctica como liberación profesional de los profesores". En IMBERNÓN, F. (coor.) Y OTROS: La formación permanente del profesorado en los paises de la CEE. ICE de la Universitat de Barcelona/Horsori. Barcelona, pp. 53-92.

GinsBurg, M. B. (1988): "El proceso de trabajo y la acción política de los educadores". Revista de Educación, no 285, pp. 315-347.

GlASSBERG, S. (1980): A view of the beginning teacher from a developmental perspective. Paper presented at the annual meeting of the American Educational Research Association. Boston.

Gómez Barnusel., A. (1972): El magisterio como profesión. Ariel. Barcelona.

Gómez, L. A. y Serra, E. (1989): "Sobre la salud mental de los profesores". Cuadernos de Pedagogía, no 175 , noviembre, pp. 60-65.

GonzÁlez Blasco, P. y GONZÁlez-ANLEO, J. (1993): El profesorado en la España actual. Informe sociológico sobre el profesorado no universitario. Fundación Santa María/SM. Madrid.

GonZÁlez Granda, J. F. (1987): "Problemas percibidos por los profesores de E.G.B. en sus primeros años de docencia". Aula Abierta, 46, pp. 77-98.

González Sanmamed, M. (1995): Formación docente: perspectivas desde el desarrollo del conocimiento y la socialización profesional. PPU. Barcelona.

GoodlaD, J. I. (ed) (1990): The Moral Dimensions of Teaching. Jossey - Bass Inc. San Francisco.

GuERRERO SERÓN, A. (1992): "Currículum y profesionalismo: los planes de estudio y la construcción social del maestro". Educación y sociedad, nº 11, pp. 45-65.

Guerrero SERón, A. (1993): "Sociología del profesorado". En GarCía de LEón, Ma a. y otros (eds): Sociología de la Educación. Barcanova. Barcelona, pp. 115-139.

Haberman, M. (1986): "Licesing teachers: Lessons from other professions". Phi Delta Kappan, 67, pp. 719-722.

HARgreAVES, A. (1992): "Time and Teachers Work; an Analysis of the Intensification Thesis", Teachers College Record, vol. 94, $\mathrm{n}^{\circ}$ 1, pp. 87-108.

- (1996): La profesión docente y la comunidad escolar: crónica de un desencuentro. Morata. Madrid.

- (1996): Profesorado, cultura y postmodernidad. Morata. Madrid.

- Fullan y Michael G., (ed.) (1992): Understanding Teacher Development. Teachers College Pres. New York.

HART, S. P. y MARShall, J. D. (1992): The question of Teacher Professionalism. EDRS Price. Illinois. U.S.A.

Hellgren, P. (1992): Developing Academic Professionals. Through the Fation Curriculum. Dept. of Teacher Education. Helsinki Univ. (Finland).

Hembling, D. W. y Gilliland, B. (1981): "Is there an identifiable stress cycle in the school year?. The Alberta Journal of Educational Research, 27, 4, pp. 324-330.

Howsam, R. B. ET AL. (1985): Educating a Profession. American Association of Colleges for teacher Education. Washington. 
Hoyle, E. (1974): "Professionality, Professionalism and Control in Teaching". London Educational Review, 3, pp. 13-19.

Huberman, M. (1989). Les cicles de vie des enseignants. Neûchatel. Delachaux.

HunT, D. E. Y JOYCE, B. R. (1981): "Teacher trainee personality and initial teaching style". En Joyce, B. R., Brown, C. C., Y PECK, L. (eds.): Flexibility in teaching. Longman. New York.

IMBERNON, F. (1994): La formación y el desarrollo profesional del profesorado. Hacia una nueva cultura profesional. Graó. Barcelona.

JARAUSCH, K. H. (1989): “Abogados, maestros e ingenieros: algunas reflexiones sobre la transformación de la Bilgunsbürgertum alemana, 1900-1950». Revista de Educación. Núm. Extraordinario, pp. 239-260.

JerLEAn, D. (1994): "If We Don't, Who Will?". Young - Children, vol. 59, n. 1.

Jover Olmeda, G. (1991): “Ámbitos de la deontología profesional docente». Teoría de la Educación, no 3 , pp. 75-92.

- (1995): "Líneas de desarrollo y fundamentación en el campo de la deontología de las profesiones educativas". Teoría de la Educación, no 7, pp. 137-152.

KING, M. B. (1994): "Locking Ourselves In. National Standars for the Teaching Profession", Teaching and Teacher Education, vol. 10, nº 1. pp. 95-108.

KYRIACOU, C. Y SUTCLIFFE, J. (1978): “Teacher stress: prevalence, sources and symptoms". British Journal of Educational Psychology, 48, pp. 159-167.

LACEY, C. (1977): The socialization of teachers. Methuen. London.

LADERRIÈRE, P. (1994): "Les politiques de quelques pays européens dans le champ de la professionnalisation". European Journal of Teacher Education, vol. 17, no 1-2, pp. 25-29.

LARSON, M. S. (1979): „Professionalism: rise and fall”. International Journal of Health Services, vol. $9, \mathrm{n}^{\circ} 4$, pp. 607-627.

LAwn, M. y OlzA, J. (1988): “'Trabajador de la enseñanza? Nueva valoración de los profesores". Revista de Educación, no 285 , pp. 191-217.

LEBERT G. (1995): Les nouvelles Sciences de l'Éducation. Éditions Nathan. Paris.

LEMLECH, J. K. (ed.) (1995): Becoming a Professional Leader. Scholastic Inc. New York.

Lerena, C. (1987): "El oficio de maestro". En OrtegA, F. y otros (comp): Manual de Sociologia de la Educación. Visor. Madrid, pp. 156-184.

LEVINE, M. (ed.) (1992): Professional Practice Schools: Linging Teacher Education and Scholl Reform. Teacher College Press, Colchester, New York.

LISTON, D. Y ZEICHNER, K. M. (1993): "La formación del profesorado y las condiciones sociales de la enseñanza.. Morata. Madrid.

LlAMAZARES, D. (1995): "Principios informadores del sistema educativo español". En CASTRO, A. (ed.): Educación como transmisión de valores. Instituto Internacional de Sociología Jurídica de Oñati. Oñati, pp. 29-78.

LOZANO SOlER, J. M. (1994): "Què vol dir professional? Marc de referència per a una ètica professional.. En VV.AA.: Què vol dir ser professsional de l'ensenyament?. Cruilla. Barcelona, pp. 29-74.

LuHmann, N. (1993): "Contingencia y autonomía”. En LuHManN, N. y SCHORR, K. E.: El sistema educativo (Problemas de reflexión). Universidad de Guadalajara. México, pp. 31-134.

LuzuRIAGa, L. (1916): Documentos para la Historia Escolar de España. Centro de Estudios Científicos. Madrid.

LYNCH, J. (1977): La educación permanente y la preparación del personal docente. Instituto de Educación de la Unesco. Hamburgo.

MANDRA, R. (1984): "Causas de inadaptación y desadaptación de los enseñantes franceses y dispositivo de ayuda puesto en marcha por el Ministerio de Educación Nacional.. En EsteVE, J. M.: Profesores en conflicto. Narcea. Madrid, pp. 213-222.

(c) Ediciones Universidad de Salamanca

Teor. educ. 10, 1998, pp. 95-144 
MARCELO GARCíA, C. (1992): Aprender a enseñar: un estudio sobre el proceso de socialización de profesores principiantes. MEC. Madrid.

- (1994): Formación del Profesorado para el cambio educativo. PPU. Barcelona.

- (1996): "Formación permanente del profesorado: pasado, presente y futuro en España". Seminario sobre Reformas educativas y formación del profesorado. Universidad de Murcia (Texto policopiado).

Marshai., T. H. (1964): Class, citizenship and social development. Doubleday. New York.

Martín-Moreno, J. y De Miguel, A. (1982): Sociología de las profesiones. Centro de Investigaciones Sociológicas. Madrid.

MEADE, E. J. (1991): «Reshaping the clinical phase of teacher preparation". Phi Delta Kappan, 72, pp. 666-669.

MeichenBaum, D. (1981): “Una perspectiva cognitivo-comportamental del proceso de socialización". Análisis y modificación de conducta. № extra, pp. 85-105.

- y CAMERON, R. (1987): "Entrenamiento en inoculación de estrés: Hacia un paradigma general para el entrenamiento en habilidades de afrontamienton. En MEICHENBAUM, D. y JAREMко, M. E.: Prevención y reducción del estrés. Bilbao. Desclée de Brouwer, pp. 107-142.

MerTens, H. (1994): "Professionalization and innovation". European Journal of Teacher Education, vol. 17, ํ․ $1 / 2$, pp. 31-33.

MialareT, G. (1983): La Formation des Enseignants. Presses Universitaires de France. Paris.

Moratinos, J. M. (1989): "El código deontológico profesional del pedagogo". Revista Española de Pedagogía, no 174, pp. 239-244.

Muller-FoHRBRODT, G. Y COLS. (1978): Der praxisschok bei junger lebrern. Kett. Stuttgart.

Nickel, H. (1981): Psicología de la conducta del profesor. Herder. Barcelona.

Noguera, J. (1984): Métodos de selección y formación de profesores. Herder. Barcelona.

- (1994): El pensamiento teórico-práctico de los formadores de profesores. PPU. Barcelona.

NovoA, A. (1994): "Les enseignants: à la recherche de leur profession". European Journal of Teacher Education, vol. 17, n⿳⺈.1/2, pp. 35-41.

Ortega Esteban, J. (1980): "Estatuto Socioprofesional del Pedagogo". La Investigación Pedagógica y la Formación de Profesores. VII Congreso Nacional de Pedagogía. Sociedad Española de Pedagogía. Madrid, pp. 373-396.

OrtegA, F. (1989): "La crisis de la profesión docente y el ascenso de los valores particularistas". En Ortega, F. y otros (comp): Manual de Sociología de la Educación. Visor. Madrid, pp. 359-370.

- (1992): “Unos profesionales en busca de profesión". Educación y sociedad, nº 11, pp. 9-21.

- y Velasco, A. (1991): La profesión de maestro. CIDE. Madrid.

Perrenoud, P. (1994): "Compétences, habitus et savoirs professionnels". European Journal of Teacher Education, vol. 17, no 1-2, pp. 45-48.

Perrone, V. (1991): A Letter to Teachers: Reflectins on Schooling and the Art of Teaching. Jossey - Bass, Inc., Publischers. San Francisco.

Petrie, H. G. (1995): Professionalization, Partnership, and Power. State University of New York Press.

PeTTY, M. Y HogBen (1980): «Explorations of semantic space with beginning teachers: a study of socialization into teaching. British Journal of Teacher Education, 6, pp. 51-61.

POPKEwITZ, T. S. (1985): “A comparative perspective on American teacher education: being a stranger in one's native land". Journal of Teacher Education, 36 (5), pp. 2-10.

- (1989): "Reformas de la Formación del profesorado y la enseñanza en Estados Unidos: Reconstitución del aparato burocrático del Estado y elaboración de un discurso político". Revista de Educación. Núm. Extraordinario, pp. 267-305.

- (1990): «Profesionalización y formación del profesorado". Revista Cuadernos de Pedagogía, no 184 , pp. 105-110. 
- (1994): "Professionalization in Teaching and Teacher Education: Some Notes on Its History, Ideology, and Potential.. Teaching and Teacher Education, vol. 10, $\mathrm{n}^{-}$1, pp. 1-14.

PORTER, A. (1980): "Aprender a enseñar. Prioridades en acción". En Goble, N. y PORTER, J.: La cambiante función del profesor. Perspectivas internacionales. Narcea. Madrid, pp. 105-183.

PRATTE, R. y RuRY, J. L. (1991): “Teachers, professionalism, and craft". Teachers College Record, 93, pp. 59-72.

RANJARD, P. (1988): "Responsabilidad y conciencia profesional de los enseñantes". Revista de Educación, no 285 , pp. 63-75.

ReCiO MuÑIz, M. (1994): "Absentismo y enfermedades profesionales". Trabajadores de la Enseñanza, $\mathrm{n}^{\circ}$ 157, pp. 22-26.

Revista de Educación (1988): Núm. Extraordinario, «Profesionalidad y profesionalización de la Enseñanza", Enero-Abril 1988, núm. 285.

Rodríguez Espinar, S. (1994): "El desarrollo profesional del Profesor Universitario: Algunas consideraciones sobre una experiencia". Revista de Enseñanza Universitaria. Instituto de Ciencias de la Educación. Universidad de Sevilla, núms. 7-8, pp. 35-56.

SÁEz CARRERAS, J. (1986): "Los educadores sociales. ¿Tecnólogos o intelectuales?". Pedagogía Social, $\mathrm{n}^{\mathrm{O}}$ 7, pp. 170-189.

SALINAS FERnÁNDEZ, D. (1994): "Reflexión del profesor: la novedad de un viejo principio". Cuadernos de Pedagogia, no 226, pp. 81-87.

SÁNCHEZ de HoRCAJO, J. J. (1985): El profesorado rural de EGB en Castilla-León. Fundación Santa María. Madrid.

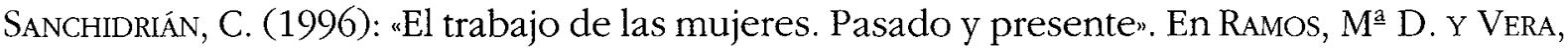
$\mathrm{M}^{\mathrm{a}} \mathrm{T}$.: Actas del Congreso Internacional del Seminario de Estudios Interdisciplinarios de la Mujer. Tomo III. Servicio de Publicaciones de la Diputación Provincial de Málaga, pp. 137-147.

SARFATTI LARSON, M. (1989): "Acerca de los expertos y los profesionales o la imposibilidad de haberlo dicho todo". Revista de Educación, no 285, pp. 199-227.

SARRAMONA LÓPEZ, J. (1980): "Estrategias no convencionales de formación del profesorado". La investigación pedagógica y la Formación de Profesores. VII Congreso Nacional de Pedagogía. Sociedad Española de Pedagogía. Madrid, pp. 439-452.

- (1990): Tecnología educativa. Una valoración crítica. Ceac. Barcelona.

- (1995): "La professionalitat pedagògica". L'educació: el repte del tercer mil.leni. Simposi Internacional. Institució Familiar d'Educació. Sitges, pp. 7-12.

Seashore, L. K. ET AL. (1994): Professionalism and Comunity: Perspectives on Reforming Urban Schools. Office of Educational Research and Inprovement (DE.). Washington, D.C.

SOCKETT, H. (1990): "Accountability, trust, and ethical codes of practice". In GOODLAD ET AL.: The moral dimension of teaching. Jossey Bass. San Francisco, pp. 224-250.

- (1994): "The Moral Base For Teacher Professionalism". Thresholds in Education, vol. 20, $\mathrm{n}^{\circ} .2-3$, pp. 2-9.

SODER, R. (1991): "The Ethics of the retoric of teacher professionalization". Teaching and Teacher Education, 7, $\mathrm{n}^{\circ}$ 3, pp. 295-300.

Sprinthall, N. A. y Thiess-Sprinthall (1983): "The teacher as an adult learner: a cognitive developmental view». En Griffin, G. A. (ed.): Staff development. University of Chicago. Chicago.

Sykes, G. (1992): "En defensa del profesionalismo docente como una opción de política educativa". Educación y Sociedad, no 11, pp. 85-96.

Sykes, U. (1994): "Creating a Climate for Change in a Major Urban School System". YoungChildrem, vol. $50, \mathrm{n}^{\circ} 1$, pp. $4-7$. 
TAYLOR, W. (1980): “La formación del personal docente: decisiones que hay que tomar”. Perspectivas, 10 (2), pp. 233-242.

TENORTH, H.-E. (1988): "Profesiones y profesionalización. Un marco de referencia para el análisis histórico del enseñante y sus organizaciones». Revista de Educación, nº 285, pp. 77-92.

TORRENTS, R. (1995): "Els docents per una escola catalana en transformació". Societat Catalana de Pedagogía. Barcelona.

TOURIÑÁN López, J. M. (1990): “La profesionalización como principio del sistema educativo y la función pedagógica". Revista de Ciencias de la Educación, $\mathrm{n}^{\circ}$ 141, pp. 9-23.

- (1987): Estatuto del profesorado. Función pedagógica y alternativas de formación. Escuela Española. Madrid.

TRILLA, J. (1992): El profesor y los valores controvertidos. Paidós. Barcelona.

VARELA, J. y ORTEGA, F. (1984): El aprendiz de maestro. MEC. Madrid.

Veenman, S. (1984): "Perceived problems of beginning teacher. Review of Educational Research, 54, 2, pp. 143-178.

VERA, J. (1988a): La crisis de la función docente. Promolibro. Valencia.

- (1988b): El profesor principiante. Promolibro. Valencia.

- (1992). "Elementos para el análisis de la imagen social de los profesores". Teoría de la Educación, vol. IV, pp. 139-149.

- (1993): "Un análisis científico-tecnológico de la investigación-acción". Teoría de la Educación, vol. V, pp. 149-158.

- (1994). "La comunicación entre el profesorado de Centro como forma de mejorar la eficacia del trabajo en equipo". Aula de Innovación Educativa, no 28-29, pp. 59-63.

VILLAR ANGULO, L. M. (1990): El profesor como profesional: formación y desarrollo profesional. Servicio de publicaciones de la Universidad de Granada. Granada.

- (1993): El Profesor como práctico reflexivo en una cultura colaborativa. Servicio de Publicaciones. Granada.

Vonk, H. (1983), "Problems of the beginning teacher". European Journal of Teacher Education, 6, (2), pp. 133-150.

- (1984): Teacher education and teacher-practice. Free University Press. Amsterdam.

- (1985): "The gap between theory and practice". European Journal of Teacher Education, 8, 3, pp. 307-317.

WaNJiRu G. Ch. (1995): La ética de la profesión docente. Estudio introductorio a la deontología de la educación. Eunsa. Pamplona.

Warken P. D. (1994): Are Professors Professional. Jessica Kingsley Publishers. London and Bristol. Pennsylvania.

WiLENSKY, H. L. (1964): "The professionalization of everyone?". The American Journal of Sociology, septiembre, pp. 137-157.

WILSON, J. Y D'ARCY, J. (1987): "Employment Conditions and Induction Opportunities". European Journal of Teacher Education, 10 (2), pp. 141-149.

WISE, A. E. (1989): "If we are ever to "professionalize" school teaching, universities must redesing education programs". The Teacher Educator, no 24 (4), pp. 29-32.

ZEICHNER, K. (1987): «Enseñanza reflexiva y experiencias de aula en la formación del profesorado". Revista de Educación, no 282, pp. 161-190.

- (1991): "Contradictions and Tensions in the Professionalization of Teaching and the Democratization of Schools". Teachers College Record, vol. 92, $\mathrm{n}^{\mathrm{9}} 3$, pp. 363-79.

- (1994): "El Maestro como profesional reflexivo". Cuadernos de Pedagogía, no 220, pp. 44-49.

ZubieTA Irún, J. C. y Susinos RADA, T. (1992): Las satisfacciones e insatisfacciones de los enseñantes. CIDE. Madrid. 